\title{
Patient population with multiple myeloma and transitions across different lines of therapy in the US: an epidemiologic model
}

\begin{tabular}{|c|c|}
\hline Journal: & Pharmacoepidemiology and Drug Safety \\
\hline Manuscript ID & PDS-15-0194.R1 \\
\hline Wiley - Manuscript type: & Original Research Article \\
\hline Date Submitted by the Author: & $\mathrm{n} / \mathrm{a}$ \\
\hline Complete List of Authors: & $\begin{array}{l}\text { Cid Ruzafa, Javier; Evidera, Retrospective Observational Studies } \\
\text { Merinopoulou, Evie; Evidera, Retrospective Observational Studies } \\
\text { Baggaley, Rebecca; London School of Hygiene \& Tropical Medicine, } \\
\text { Department of Infectious Disease Epidemiology } \\
\text { Leighton, Pamela; Evidera, Retrospective Observational Studies } \\
\text { Werther, Winifred; Onyx Pharmaceuticals, Inc., an Amgen subsidiary, } \\
\text { Epidemiology } \\
\text { Felici, Diana; Onyx Pharmaceuticals, Inc., an Amgen subsidiary, } \\
\text { Epidemiology } \\
\text { Cox, Andrew; Evidera, Retrospective Observational Studies }\end{array}$ \\
\hline Keywords: & Epidemiology, multiple myeloma, prevalence, model, treatment line \\
\hline Abstract: & $\begin{array}{l}\text { Multiple myeloma (MM) is a progressive, malignant neoplasia with a } \\
\text { worldwide, age-standardized annual incidence of } 1.5 \text { per } 100,000 \\
\text { individuals and 5-year prevalence around } 230,000 \text { patients. Main favorable } \\
\text { prognostic factors are younger age, low-moderate cytogenetic risk, and } \\
\text { undergoing stem cell transplantation. Our aim was to estimate the size of } \\
\text { the patient population with MM eligible to receive a new MM therapy at } \\
\text { different lines of therapy in the US. } \\
\text { Methods: } \\
\text { We constructed a compartmental, differential equation model representing } \\
\text { the flow of MM patients from diagnosis to death, via two possible treatment } \\
\text { pathways and distinguished in four groups based on prognostic factors. } \\
\text { Parameters were obtained from published references, available statistics, } \\
\text { and assumptions. The model was used to estimate number of diagnosed } \\
\text { MM patients and number of patient transitions from one line of therapy to } \\
\text { the next over one-year. Model output included } 95 \% \text { credible intervals (CI) } \\
\text { from probabilistic sensitivity analyses. } \\
\text { Results: } \\
\text { The base-case estimates were } 80,219 \text { patients living with MM, including } \\
70,375 \text { on treatment, } 780 \text { symptomatic untreated patients, and } 9,064 \\
\text { asymptomatic untreated patients. Over a one-year period, the number of } \\
\text { MM patients on treatment line } 1 \text { was estimated at } 23,629 \text { (CI } 22,236- \\
25,029 \text { ), and the number of transitions from treatment line } 1 \text { to treatment } \\
\text { line } 2 \text { estimated at } 14,423 \text {. } \\
\text { Conclusions: }\end{array}$ \\
\hline
\end{tabular}


2

3

4

5

6

7

8

9

10

The size of the patient population with MM on different lines of therapy and in-patient subgroups of interest estimated from this epidemiologic model can be used to assess the number of patients who could benefit from new MM therapies and their corresponding budgetary impact.

\section{SCHOLARONE ${ }^{\text {m }}$}

Manuscripts 


\title{
Patient population with multiple myeloma and transitions across different lines of therapy in the US: an epidemiologic model
}

Running Head: Multiple myeloma lines of therapy: an epidemiologic model

\author{
Cid Ruzafa $\mathrm{J}^{1}$, Merinopoulou $\mathrm{E}^{1}$, Baggaley $\mathrm{RF}^{2}$, Leighton $\mathrm{P}^{1}$, Werther $\mathrm{W}^{3}$, Felici $\mathrm{D}^{3}$, Cox $\mathrm{A}^{1}$ \\ ${ }^{1}$ Retrospective Observational Studies, Evidera, London, UK; ${ }^{2}$ Department of Infectious \\ Disease Epidemiology, London School of Hygiene \& Tropical Medicine, London, UK; ${ }^{3}$ Onyx \\ Pharmaceuticals, Inc., an Amgen subsidiary, South San Francisco, CA, USA
}

Keywords: Epidemiology, multiple myeloma, prevalence, model, treatment line

\section{Key Points:}

- The estimated number of patients with MM in the US provided by the epidemiology model was consistent with the figure reported by SEER.

- The distribution of the patient population with MM on different lines of therapy and in patient subgroups of interest can be estimated from the epidemiologic model.

- The size of the patient population with MM on different lines of therapy and in patient subgroups can be used to assess the number of patients who could benefit from new MM therapies, information required for budget impact analysis and to support the planning of healthcare services.

Word Count: 2,751 (excluding abstract, references, tables, etc.)

\section{Sponsors/Conflict of Interest:}

This work was funded by Onyx Pharmaceuticals. Cid Ruzafa J, Merinopoulou E, Baggaley $R$, Leighton $P$, and Cox $A$ were employed by Evidera and served as consultants to Onyx Pharmaceuticals. Werther $\mathrm{W}$ and Felici $\mathrm{D}$ were employed by and own stock in Onyx Pharmaceuticals.

\section{Corresponding Author:}

Javier Cid

Evidera

Metro Building, 6th Floor, 1 Butterwick London, UK W6 8DL Javier.Cid@evidera.com

Tel +34 932213441

$\mathrm{Fax}+44(0) 2085765195$

This research represents original work and has not been published elsewhere in full or in part, besides in abstract form. Javier Cid takes responsibility for the integrity of the work as a whole. 
ABSTRACT

Purpose:

Multiple myeloma (MM) is a progressive, malignant neoplasia with a worldwide, agestandardized annual incidence of 1.5 per 100,000 individuals and 5-year prevalence around 230,000 patients. Main favorable prognostic factors are younger age, low-moderate cytogenetic risk, and undergoing stem cell transplantation. Our aim was to estimate the size of the patient population with MM eligible to receive a new MM therapy at different lines of therapy in the US.

\section{Methods:}

We constructed a compartmental, differential equation model representing the flow of MM patients from diagnosis to death, via two possible treatment pathways and distinguished in four groups based on prognostic factors. Parameters were obtained from published references, available statistics, and assumptions. The model was used to estimate number of diagnosed MM patients and number of patient transitions from one line of therapy to the next over one-year. Model output included 95\% credible intervals $(\mathrm{Cl})$ from probabilistic sensitivity analyses.

\section{Results:}

The base-case estimates were 80,219 patients living with $\mathrm{MM}$, including 70,375 on treatment, 780 symptomatic untreated patients, and 9,064 asymptomatic untreated patients. Over a one-year period, the number of MM patients on treatment line 1 was estimated at $23,629(\mathrm{Cl} 22,236-25,029)$, and the number of transitions from treatment line 1 to treatment line 2 estimated at 14,423 .

\section{Conclusions:}

The size of the patient population with MM on different lines of therapy and in-patient subgroups of interest estimated from this epidemiologic model can be used to assess the number of patients who could benefit from new MM therapies and their corresponding budgetary impact.

Word count: 250 


\section{INTRODUCTION}

Multiple myeloma ( $\mathrm{MM})$ is a progressive, hematologic malignancy originating from plasma cells and with the most negative long-term prognosis among lymphoid malignancies. ${ }^{1,2} \mathrm{MM}$ accounts for approximately $1 \%$ of all cancers and $10-12 \%$ of hematologic malignancies, with a worldwide age-standardized annual incidence of 1.5 per 100,000 or estimates of around 115,000 new cases per year, a rather small number compared to other cancers and chronic conditions. . $^{2-4} \mathrm{MM}$ has an estimated worldwide 5-year prevalence of around 230,000 patients. ${ }^{4}$ Older age is associated with unfavorable outcomes, ${ }^{1,5}$ and there are no apparent prognostic differences associated with gender. ${ }^{1}$ The presence of certain chromosomal abnormalities is also a negative prognostic factor. ${ }^{5-8}$

MM treatment is intended to control the symptomatic disease and minimize organ damage; however, relapse is likely. From high-dose therapy followed by autologous stem cell transplantation for candidates in good condition, ${ }^{7,9}$ to allogeneic stem cell transplantation (SCT) in young patients with high-risk disease, ${ }^{7,10}$ and to novel agents introduced in recent years, ${ }^{2,7,11,12}$ all are associated with prolonged survival of patients with this incurable disease..$^{5,7,9,13-15}$ More than 10 drugs and a greater number of drug combinations offer therapeutic options to patients who have relapsed or are refractory to previous treatments and can result in patients receiving multiple lines of therapy.,7 The prevalence of MM is likely to increase as a result of ageing societies and improved survival of patients. Multiple lines of therapy for an increasing number of patients with $\mathrm{MM}$ translate into increasing resource requirements at subsequent lines of therapy ${ }^{16}$ and competition among MM treatment alternatives on pharmacoeconomic grounds. ${ }^{17-19}$

Epidemiologic information including disease incidence, prevalence and mortality are inputs for burden of disease and cost-effectiveness analyses that aim to inform policy-making, planning and research prioritization in health care. ${ }^{20}$ Previous studies have used mathematical modeling techniques to project the prevalence of chronic conditions such as diabetes and chronic kidney disease into the near or distant future. ${ }^{21-23}$ In oncology, an epidemiologic model was used to estimate disease prevalence and the absolute number of patients at first-, second-, and third line of therapy for gastrointestinal stromal tumors, ${ }^{24}$ providing useful information for budget impact analysis and healthcare services planning. ${ }^{20}$ In the absence of current data on the number of patients with MM by line of therapy in the US, the objectives of this study were to estimate the current number of patients with MM who are potentially eligible to receive a new MM therapy at different lines of therapy in the US, and to estimate the corresponding number of patient transitions from one line of therapy to the next over a one-year period. 


\section{METHODS}

\section{Model Overview}

The size of the patient population with MM in the US across lines of therapy and the number of patient transitions from one line of therapy to the next was estimated using a compartmental model that represents the flow of patients with MM from disease occurrence to death, via two possible treatment pathways (SCT eligible; SCT non-eligible) (Figure 1). To account for the impact of different risk factors on disease progression, ${ }^{1,5-8}$ the model distinguished four groups of patients based on age at diagnosis and cytogenetic risk: older or younger than 65 years of age, and high or low/standard cytogenetic risk (Figure 1, as depicted by dotted lines).

All newly diagnosed patients with $\mathrm{MM}$ enter the model as symptomatic or asymptomatic. Asymptomatic patients are assumed to receive no treatment until symptom occurrence. Symptomatic patients can transition through two treatment pathways depending on whether they are eligible for an SCT or not. Patients in both pathways progress from one line of therapy to the next as they relapse. For patients eligible for a SCT, the first line of therapy represents induction, SCT and maintenance therapy post SCT. In each treatment line, patients are allowed to die from background mortality or mortality related to their condition. Eventually, all patients will die since the model assumes there is no cure for MM.

The model consists of a set of four differential equations which represent a mean approximation of the expected number of asymptomatic, symptomatic untreated, individuals who initiated on first line, and on subsequent treatment lines through time (Appendix A). The model parameters include estimates of MM incidence, mortality, and time to next treatment line (Table 1, Appendix A). The base case parameter values are shown in Table 1.

This model includes a number of assumptions necessary for its correct interpretation:

- Results for all lines beyond 17 are incorporated into the 17 th line.

- Patients on the SCT pathway may have up to two SCTs along their line therapy trajectory.

- Asymptomatic MM (smoldering) is explicitly modeled, but no treatment is given.

- Patterns of co-morbidities (e.g., peripheral neuropathy) are not explicit.

- The model tracks time between starting one treatment line and starting the next. Treatment breaks and permanent discontinuations are not explicitly modelled.

- There is no stratification for academic versus community care (for settings where these different care types exist).

- Line of therapy is determined by disease progression, relapse, or drug toxicity resulting in a modification of the planned therapeutic approach. ${ }^{25}$

- Being in the high-risk cytogenetic group does not affect SCT eligibility. 
- Survival probabilities are characterized by an exponential function.

- The length of each treatment line is shorter than the previous one. Minimum length of a treatment line is approximately one week (1/50 year).

- Relative rate of patients transitioning from one line to another is constant across all lines.

- MM-related mortality while symptomatic before first line treatment initiation is slightly higher $(\approx 10 \%)$ than MM-related mortality while asymptomatic.

- MM attributable mortality declines in the first year because of plasma cell leukemia patient depletion from the cohort. It is relatively constant over the subsequent years $\left(\approx 10 \%\right.$ increase) but then increases, especially from the $6^{\text {th }}$ line of therapy and beyond

- Forecasts are at the population level and not at the individual level.

\section{Data Sources}

To estimate the overall number of patients with $\mathrm{MM}$, we used the incidence of MM obtained from Surveillance Epidemiology and End Results (SEER) Cancer Statistics ${ }^{26}$ applied to the 2013 US population estimate from the US Census Bureau. ${ }^{27}$ Mortality rates were obtained from 2007 US National Vital Statistics. ${ }^{28}$ Other model parameters were obtained from targeted literature searches (Table 1). For each of these parameters, one or more references were identified from the literature. Internal validity of the parameter estimates obtained from the literature (or the degree to which the referenced studies are free from systematic error) is supported by the peer review process of such studies, consistency of results, and for some parameters, information provided from interviews with MM experts and market research surveys. External validity of the parameter estimates (or the degree to which those estimates can be applied to the overall population) is also expected, since the parameters' base-case values were chosen around mid-range values and the study results were consistent. Some references provided data in the format required by the model, while others required transformation. For example, survival figures expressed as percentage of surviving patients at a specific time after diagnosis or treatment initiation required transformation into yearly rates before they could be included in the model. No ethical committee approval was necessary for this study.

\section{Sensitivity Analysis}

Parametric uncertainty analyses were conducted through probabilistic sensitivity analysis (PSA). The PSA was performed on key selected model parameters ${ }^{29}$ using Latin hypercube sampling (LHS).$^{30}$ This process involved two steps: first, parameters expected to influence model output were selected for inclusion in the PSA, and partial rank correlation coefficients (PRCCs) were then computed (Appendix B, Figure B-1) to illustrate the parameters that were the greatest sources of heterogeneity in model output. ${ }^{31}$ Secondly, the PSA consisted 
of varying the parameter values by sampling 1000 times from distributions specified by the mean value (deterministic model input) and standard errors (Appendix B, Table B2).

Standard errors were selected to describe parameter variability observed in the data sources and expected in the broad population of patients with MM. Distributions were determined by the characteristics of the parameter and experience (e.g. beta distributions are usually considered for binomial data; gamma or log normal for right skew parameters; log normal for hazard ratios. ${ }^{32}$ )

\section{Model Outcomes}

Model outcomes include the size of the patient population with MM potentially eligible to receive a MM therapy at different lines of therapy in the US, as well as the corresponding number of patient transitions from one line of therapy to the next over a one-year period. The model is designed to report outcomes at equilibrium, which is judged to have been achieved when the model reaches a steady state, in that the number of patients in each line no longer fluctuates and remains stable. All model outcomes are stratified by the eight subgroups of interest resulting from the combination of SCT eligibility, age group, and cytogenetic risk group. Model outcomes also include 95\% credible intervals (analogous to a confidence interval with estimates obtained from the sampling results) from the PSA for both the number of patients and their transitions at different lines of therapy. Ninety five percent (95\%) credible intervals were defined by the upper and lower bounds of the distribution of model outcomes from the PSA leaving $2.5 \%$ of the values below and above, respectively.

\section{RESULTS}

\section{Prevalence of MM}

Model results are presented in Table 2. An estimated 80,219 patients were living with diagnosed MM in the US, of whom 70,375 patients were receiving treatment, 780 patients were symptomatic untreated and 9,064 patients were asymptomatic who are untreated and would be monitored for progression to symptomatic MM. Patient numbers stratified by SCT eligibility, age group, and cytogenetic risk group are shown in Table 2. Additionally, the model estimated that 19,330 patients with MM would die over a one-year period from background mortality and mortality attributable to MM.

\section{Patient Transitions from One Line of Therapy to the Next}

Table 3 reports the number of patient transitions from one line of therapy to the next over a one-year period, estimating that the total number of transitions experienced by the above patient population would be 96,259 . A total of 18,689 patients diagnosed with MM are estimated to initiate first line therapy over a one-year period. Patients entering into treatment 
line 17 and beyond were estimated at 167. Results stratified by SCT eligibility, age group, and cytogenetic risk group are also presented in Table 3.

\section{PSA results}

The results of the PSA are in Table 4, estimating 95\% credible intervals $(\mathrm{Cl})$ for numbers of MM patients and the numbers of patient transitions from one line of therapy to the next. The results corresponding to the eight strata of interest defined by SCT eligibility, age group, and cytogenetic risk group are shown in Appendix C. The PSA model runtime was around three hours.

\section{DISCUSSION}

The current estimated number of patients with MM in the US is 80,219 , with 70,375 on different lines of therapy. Over a one-year period, 19,330 deaths from all causes would be expected as well as 14,423 transitions from line 1 into line 2 . The estimated number of patients initiating line 1 of therapy over one year is 18,689 . Beyond line 17 of treatment, as anticipated, the patient prevalence was close to 0 , although the number of transitions over a one year period could be larger as a consequence of the short time spent in those lines of therapy when the condition is so advanced.

The model estimates of the patient distribution across the different lines of therapy, from the first to $17^{\text {th }}$ line and beyond, at a snapshot in time, differed from the patient transition breakdown over a one-year period. For early lines of therapy, lines 1 and 2, the number of patient transitions over a one-year period was smaller than the number of patients at a point in time, as a consequence of these patients spending long periods on treatment, or without receiving treatment but free of disease progression and drug toxicity. ${ }^{25}$ At subsequent lines of therapy, the number of patient transitions decreased more slowly than the number of patients reflecting that the average patient spends shorter periods on successive treatment lines and eventually can transition through several lines of therapy over a one-year period. The estimated number of patients with MM in the US provided by the model, 80,219, was consistent with the figure estimated by SEER for 2014 of 83,367 patients. Conversely, the number of patients with MM who died of this disease over a one-year period was estimated at 11,090 (SEER data from 2014), ${ }^{26}$ while the model estimate was 16,670 . This difference is larger than expected because one would anticipate that the number of deaths over a oneyear period is somehow lower than the number of new patients being diagnosed, as a result of the range of novel therapeutic alternatives providing increased patient survival over time. The expected small difference between incident cases and patient mortality would translate into a continuous steady increase of the prevalence of MM. The observed large difference in 
the SEER data between incident cases and patient mortality would result in the prevalence of patients with MM increasing greatly over a short period. We hypothesize that the large difference between the mortality estimates of the model and those of SEER could be attributable to SEER reporting only mortality attributed to MM and not all mortality experienced by patients with MM, and also to a proportion of deaths caused by MM not being correctly classified as such (resulting in apparently increased background mortality among patients with MM).

We have not identified any other epidemiologic models reporting on patients with $\mathrm{MM}$. Nevertheless, there are several studies reporting on the use of epidemiologic models for other oncologic conditions such as prostate cancer, ${ }^{33,34}$ breast cancer, ${ }^{35}$ Hodgkin's lymphoma, ${ }^{36,37}$ chronic myeloid leukemia, ${ }^{38}$ and gastrointestinal stromal tumors. ${ }^{24}$ The rationale for developing such models is consistent with the objectives of the model presented in this paper: while the epidemiology of these conditions is well documented, estimates of patient numbers and their distribution across subgroups of interest are scarce in the literature. ${ }^{24,33,35-37}$ Other research groups have developed similar models for such predictive purposes. $^{34,38}$

Estimates of numbers of patients in groups of interest produced by epidemiologic models can inform budget impact analysis and support planning of healthcare services by limiting the uncertainty associated with identifying patient numbers eligible for a given treatment. ${ }^{20,34}$ This contribution can be especially relevant for conditions that have low frequency, and hence are difficult to study, but could qualify for orphan designation and the corresponding support for research and treatment development. ${ }^{24,39}$

The model used has a complex structure and requires a large number of parameters. This is the consequence of modelling a complex condition whose treatment is also complex. $A$ positive aspect is that the reported estimates provide a detailed picture of the patient population with MM. On the other hand, complexity is a limitation when it comes to finding supportive data for the parameters that inform the model. As a consequence, some parameters are supported by only one or a few sources. This limitation is common to other modeling studies. ${ }^{24}$ Some prognostic factors of the condition such as tumor staging or renal function ${ }^{5}$ were not included separately in the model. One limitation of the model to estimate the real difference between incident cases and patient mortality is that, by definition, in the model at equilibrium the number of incident patients with MM is the same as the number of patients dying from MM and background mortality combined. Using this dynamic model to look at projections for how the MM patient population will change over time would be of interest but it is not within the scope of this project. 
Further research on the epidemiology of patients with MM will support more robust parameter estimates that can be used in this and other models. Other parameters may become pertinent to modeling prevalence of lines of therapy in patients with MM, which may warrant additional research and model development. Different stratification variables, such as disease stage or new risk classification, may prove important in further research.

Additionally, future real world study results reporting on patient population and subpopulations at different lines of therapy and transitioning across those lines will contribute data to validate the model outcomes.

In summary, the reported epidemiologic model estimates the size and the distribution of the patient population with MM stratified by subgroups of interest and the patients transitioning from one line of therapy to the next, corresponding to multiple disease relapses or treatment intolerances, and increasing burden as the condition progresses. This information can be used to assess the number of patients who could benefit from new MM therapies and their corresponding budgetary impact. 


\section{References}

1. Monnereau A, Troussard X, Belot A, et al. Unbiased estimates of long-term net survival of hematological malignancy patients detailed by major subtypes in France. International journal of cancer. Journal international du cancer. 2013;132(10):23782387.

2. Palumbo A, Anderson K. Multiple myeloma. The New England journal of medicine. 2011;364(11):1046-1060.

3. Alexander DD, Mink PJ, Adami HO, et al. Multiple myeloma: a review of the epidemiologic literature. International journal of cancer. Journal international du cancer. 2007;120 Suppl 12:40-61.

4. GLOBOCAN. 2012 Incidence. 2012; http://globocan.iarc.fr/Pages/fact sheets population.aspx. Accessed November 7, 2014.

5. Mikhael JR, Dingli D, Roy V, et al. Management of newly diagnosed symptomatic multiple myeloma: updated Mayo Stratification of Myeloma and Risk-Adapted Therapy (mSMART) consensus guidelines 2013. Mayo Clinic proceedings. 2013;88(4):360-376.

6. Avet-Loiseau H, Hulin C, Campion L, et al. Chromosomal abnormalities are major prognostic factors in elderly patients with multiple myeloma: the intergroupe francophone du myelome experience. Journal of clinical oncology : official journal of the American Society of Clinical Oncology. 2013;31(22):2806-2809.

7. Engelhardt M, Terpos E, Kleber M, et al. European Myeloma Network recommendations on the evaluation and treatment of newly diagnosed patients with multiple myeloma. Haematologica. 2014;99(2):232-242.

8. Kapoor P, Fonseca R, Rajkumar SV, et al. Evidence for cytogenetic and fluorescence in situ hybridization risk stratification of newly diagnosed multiple myeloma in the era of novel therapie. Mayo Clinic proceedings. 2010;85(6):532-537.

9. Barlogie B, Attal M, Crowley J, et al. Long-term follow-up of autotransplantation trials for multiple myeloma: update of protocols conducted by the intergroupe francophone du myelome, southwest oncology group, and university of arkansas for medical sciences. Journal of clinical oncology : official journal of the American Society of Clinical Oncology. 2010;28(7):1209-1214.

10. Bashir $\mathrm{Q}$, Khan $\mathrm{H}$, Orlowski RZ, et al. Predictors of prolonged survival after allogeneic hematopoietic stem cell transplantation for multiple myeloma. American journal of hematology. 2012;87(3):272-276.

11. El Mahou S, Attal M, Jamard B, et al. Do new therapeutic approaches (autotransplants, thalidomide, dexamethasone) improve the survival of patients with multiple myeloma followed in a rheumatology department? Clinical rheumatology. 2006;25(2):175-182. 
12. Kumar S, Flinn I, Richardson PG, et al. Randomized, multicenter, phase 2 study (EVOLUTION) of combinations of bortezomib, dexamethasone, cyclophosphamide, and lenalidomide in previously untreated multiple myeloma. Blood. 2012;119(19):4375-4382.

13. Kaya $\mathrm{H}$, Peressini $\mathrm{B}$, Jawed I, et al. Impact of age, race and decade of treatment on overall survival in a critical population analysis of 40,000 multiple myeloma patients. International journal of hematology. 2012;95(1):64-70.

14. Lonial S, Anderson KC. Association of response endpoints with survival outcomes in multiple myeloma. Leukemia. 2014;28(2):258-268.

15. Brenner H, Gondos A, Pulte D. Recent major improvement in long-term survival of younger patients with multiple myeloma. Blood. 2008;111(5):2521-2526.

16. Gaultney JG, Franken MG, Tan SS, et al. Real-world health care costs of relapsed/refractory multiple myeloma during the era of novel cancer agents. Journal of clinical pharmacy and therapeutics. 2013;38(1):41-47.

17. Green C, Bryant J, Takeda A, et al. Bortezomib for the treatment of multiple myeloma patients. Health technology assessment. 2009;13 Suppl 1:29-33.

18. Mehta J, Duff SB, Gupta S. Cost effectiveness of bortezomib in the treatment of advanced multiple myeloma. Managed care interface. 2004;17(9):52-61.

19. Moller J, Nicklasson L, Murthy A. Cost-effectiveness of novel relapsed-refractory multiple myeloma therapies in Norway: lenalidomide plus dexamethasone vs bortezomib. Journal of medical economics. 2011;14(6):690-697.

20. Cid Ruzafa J, Cox A, Merinopoulou E, Baggaley RF, Leighton P, Desai K. An epidemiologic modelling application to pharmacoeconomics for improved healthcare planning. Value in Health. 2014;17(7):A587.

21. Boyle JP, Thompson TJ, Gregg EW, Barker LE, Williamson DF. Projection of the year 2050 burden of diabetes in the US adult population: dynamic modeling of incidence, mortality, and prediabetes prevalence. Population health metrics. 2010;8:29.

22. Brinks R, Tamayo T, Kowall B, Rathmann W. Prevalence of type 2 diabetes in Germany in 2040: estimates from an epidemiological model. European journal of epidemiology. 2012;27(10):791-797.

23. Levy AR, Perkins RM, Johnston KM, et al. An epidemiologic model to project the impact of changes in glomerular filtration rate on quality of life and survival among persons with chronic kidney disease. International journal of nephrology and renovascular disease. 2014;7:271-280.

24. Starczewska Amelio JM, Cid Ruzafa J, Desai K, et al. Prevalence of gastrointestinal stromal tumour (GIST) in the United Kingdom at different therapeutic lines: an epidemiologic model. BMC cancer. 2014;14:364. 
25. Rajkumar SV, Harousseau JL, Durie B, et al. Consensus recommendations for the uniform reporting of clinical trials: report of the International Myeloma Workshop Consensus Panel 1. Blood. 2011;117(18):4691-4695.

26. National Cancer Institute (NCl). SEER Cancer Statistics Factsheets: Myeloma. http://seer.cancer.gov/statfacts/html/mulmy.html. Accessed November 7, 2014.

27. U.S. Census Bureau Population Division. Annual Estimates of the Population for the US, Regions, States, and Puerto Rico: April 1, 2010 to July 1, 2013 (NST-EST201301). Release Date: December 2013.; http://www.census.gov/popest/data/national/totals/2013/index.html Accessed November 7, 2014.

28. CDC/NCHS. National Vital Statistics System, Mortality. http://www.cdc.gov/nchs/data/dvs/MortFinal2007 Worktable23r.pdf. Accessed November 7, 2014.

29. McKay MD, Beckman RJ, Conover WJ. A comparison of three methods for selecting values of input variables in the analysis of output from a computer code.

Technometrics (JSTOR Abstract). Am Stat Assoc. 1979;21(2):239-245.

30. Blower SM, Dowlatabadi H. Sensitivity and uncertainty analysis of complex models of disease transmission: an HIV model, as an example. Int Stat Rev. 1994;62:229-243.

31. Iman RL, Helton JC, Campbell JE. An approach to sensitivity analysis of computer models: part I - introduction, input variable selection and preliminary assessment. $J$ Qual Technol. 1981;13(174-183).

32. Briggs $\mathrm{AH}$, Weinstein MC, Fenwick EA, et al. Model parameter estimation and uncertainty analysis: a report of the ISPOR-SMDM Modeling Good Research Practices Task Force Working Group-6. Med Decis Making. 2012;32(5):722-732.

33. Cure S, Martin M, Bracco A, Brown J, Kearney M. An epidemiological model of prostate cancer and progression to bone metastases in the United Kingdom. Value in Health. 2011;14:PCN18.

34. Vitale V, Asano E, Pereira ML. Budget impact analysis of abiraterone acetate in metastatic castration-resistant prostate cancer patients previously treated with docetaxel from the perspective of the Brazilian private health care system. Value in Health. 2013;16:A665.

35. Martin M, Kearney M, Bracco A, Brown J. An epidemiological model of breast cancer and progression to bone metastases in the United Kingdom. Value in Health. 2011;14:PCN19.

36. Abbe A, Lee A, Hamed A, Neumann F, Olivares R, Engert A. Epidemiologic modelling estimating the number of patients with relapsed Hodgkin lymphoma after autologous stem cell transplant in 5 European countries. JNCCN. 2013;11(3):243244.

37. Lee A, Abbe A, Hamed A, Neumann F, Olivares R, Younes A. Epidemiologic model estimating number of Hodgkin lymphoma patients who relapsed after autologous 
stecm cell transplant in the United States. Journal of clinical oncology : official journal of the American Society of Clinical Oncology. 2013;31(15):e12554.

38. Fagnani F, Sartre J, Rota C, Bregman B, Gaudin AF. Projection of the patients' population treated for chronic myeloid leukemia in chronic phase in France: an epidemiological model at the horizon 2015. Value in Health. 2011:A233.

39. EMA. Human regulatory: orphan designation. http://www.ema.europa.eu/ema/index.jsp?curl=pages/regulation/general/general con tent 000029.jsp\&mid=WC0b01ac05800240ce. Accessed November 7, 2014.

40. Avet-Loiseau H, Attal M, Moreau P, et al. Genetic abnormalities and survival in multiple myeloma: the experience of the Intergroupe Francophone du Myelome. Blood. 2007;109(8):3489-3495.

41. Avet-Loiseau $\mathrm{H}$, Soulier J, Fermand JP, et al. Impact of high-risk cytogenetics and prior therapy on outcomes in patients with advanced relapsed or refractory multiple myeloma treated with lenalidomide plus dexamethasone. Leukemia. 2010;24(3):623628.

42. Gonsalves WI, Rajkumar SV, Gupta V, et al. Quantification of clonal circulating plasma cells in newly diagnosed multiple myeloma: implications for redefining highrisk myeloma. Leukemia. 2014;28(10):2060-2065.

43. Kapoor P, Kumar S, Fonseca R, et al. Impact of risk stratification on outcome among patients with multiple myeloma receiving initial therapy with lenalidomide and dexamethasone. Blood. 2009;114(3):518-521.

44. Konigsberg R, Zojer N, Ackermann J, et al. Predictive role of interphase cytogenetics for survival of patients with multiple myeloma. Journal of clinical oncology : official journal of the American Society of Clinical Oncology. 2000;18(4):804-812.

45. Kumar SK, Lee JH, Lahuerta JJ, et al. Risk of progression and survival in multiple myeloma relapsing after therapy with IMiDs and bortezomib: a multicenter international myeloma working group study. Leukemia. 2012;26(1):149-157.

46. Sellner L, Heiss C, Benner A, et al. Autologous retransplantation for patients with recurrent multiple myeloma: a single-center experience with 200 patients. Cancer. 2013;119(13):2438-2446.

47. Karlin L, Soulier J, Chandesris $\mathrm{O}$, et al. Clinical and biological features of $t(4 ; 14)$ multiple myeloma: a prospective study. Leukemia \& lymphoma. 2011;52(2):238-246.

48. Kyle RA, Remstein ED, Therneau TM, et al. Clinical course and prognosis of smoldering (asymptomatic) multiple myeloma. The New England journal of medicine. 2007;356(25):2582-2590.

49. Liwing J, Uttervall K, Lund J, et al. Improved survival in myeloma patients: starting to close in on the gap between elderly patients and a matched normal population. British journal of haematology. 2014;164(5):684-693. 
50. Mateos MV, Hernandez MT, Giraldo P, et al. Lenalidomide plus dexamethasone for high-risk smoldering multiple myeloma. The New England journal of medicine. 2013;369(5):438-447.

51. Al-Hamadani M, Hashmi SK, Go RS. Use of autologous hematopoietic cell transplantation as initial therapy in multiple myeloma and the impact of socio-geodemographic factors in the era of novel agents. American journal of hematology. 2014;89(8):825-830.

52. Ludwig H, Durie BG, Bolejack V, et al. Myeloma in patients younger than age 50 years presents with more favorable features and shows better survival: an analysis of 10549 patients from the International Myeloma Working Group. Blood. 2008;111(8):4039-4047.

53. Armoiry X, Fagnani F, Benboubker L, et al. Management of relapsed or refractory multiple myeloma in French hospitals and estimation of associated direct costs: a multi-centre retrospective cohort study. Journal of clinical pharmacy and therapeutics. 2011;36(1):19-26.

54. Wu W, Merriman K, Nabaah A, et al. The association of diabetes and anti-diabetic medications with clinical outcomes in multiple myeloma. British journal of cancer. 2014;111(3):628-636.

55. Kristinsson SY, Landgren O, Dickman PW, Derolf AR, Bjorkholm M. Patterns of survival in multiple myeloma: a population-based study of patients diagnosed in Sweden from 1973 to 2003. Journal of clinical oncology : official journal of the American Society of Clinical Oncology. 2007;25(15):1993-1999.

56. Turesson I, Velez R, Kristinsson SY, Landgren O. Patterns of improved survival in patients with multiple myeloma in the twenty-first century: a population-based study. Journal of clinical oncology : official journal of the American Society of Clinical Oncology. 2010;28(5):830-834.

57. Bergsagel PL, Mateos MV, Gutierrez NC, Rajkumar SV, San Miguel JF. Improving overall survival and overcoming adverse prognosis in the treatment of cytogenetically high-risk multiple myeloma. Blood. 2013;121(6):884-892.

58. Hebraud B, Leleu X, Lauwers-Cances V, et al. Deletion of the 1 p32 region is a major independent prognostic factor in young patients with myeloma: the IFM experience on 1195 patients. Leukemia. 2014;28(3):675-679.

59. Sasaki K, Lu G, Saliba RM, et al. Impact of $t(11 ; 14)(q 13 ; q 32)$ on the outcome of autologous hematopoietic cell transplantation in multiple myeloma. Biology of blood and marrow transplantation : journal of the American Society for Blood and Marrow Transplantation. 2013;19(8):1227-1232.

60. Drake MB, lacobelli S, van Biezen A, et al. Primary plasma cell leukemia and autologous stem cell transplantation. Haematologica. 2010;95(5):804-809.

61. El-Cheikh J, Crocchiolo R, Furst S, et al. Long-term outcome after allogeneic stemcell transplantation with reduced-intensity conditioning in patients with multiple myeloma. American journal of hematology. 2013;88(5):370-374. 
62. Kumar SK, Lacy MQ, Dispenzieri A, et al. Early versus delayed autologous transplantation after immunomodulatory agents-based induction therapy in patients with newly diagnosed multiple myeloma. Cancer. 2012;118(6):1585-1592.

63. Richardson PG, Barlogie B, Berenson J, et al. Clinical factors predictive of outcome with bortezomib in patients with relapsed, refractory multiple myeloma. Blood. 2005;106(9):2977-2981.

64. Richardson PG, Sonneveld P, Schuster MW, et al. Safety and efficacy of bortezomib in high-risk and elderly patients with relapsed multiple myeloma. British journal of haematology. 2007;137(5):429-435.

65. San Miguel JF, Schlag R, Khuageva NK, et al. Persistent overall survival benefit and no increased risk of second malignancies with bortezomib-melphalan-prednisone versus melphalan-prednisone in patients with previously untreated multiple myeloma. Journal of clinical oncology : official journal of the American Society of Clinical Oncology. 2013;31(4):448-455.

66. San Miguel JF, Schlag R, Khuageva NK, et al. Bortezomib plus melphalan and prednisone for initial treatment of multiple myeloma. The New England journal of medicine. 2008;359(9):906-917. 


\section{TABLES}

Table 1. Model Base Case Parameter Values for the US

\begin{tabular}{|c|c|c|c|}
\hline Parameter & Base Case & Units & Reference \\
\hline \multicolumn{4}{|l|}{ Population } \\
\hline Population size & $316,128,839$ & persons & 27 \\
\hline Background death rate of adults $40-64$ years & 0.008 & $\begin{array}{l}\text { proportion per } \\
\text { year }\end{array}$ & 28 \\
\hline Background death rate of adults $\geq 65$ years & 0.060 & $\begin{array}{l}\text { proportion per } \\
\text { year }\end{array}$ & 28 \\
\hline \multicolumn{4}{|l|}{ MM epidemiology } \\
\hline Incidence of MM & 0.000061 & $\begin{array}{l}\text { proportion per } \\
\text { year }\end{array}$ & 5,26 \\
\hline $\begin{array}{l}\text { Proportion patients }<65 \text { years at MM } \\
\text { diagnosis }\end{array}$ & $38.00 \%$ & $\%$ & 5,26 \\
\hline $\begin{array}{l}\text { Proportion in high cytogenetic risk group at } \\
\text { MM diagnosis }\end{array}$ & $35.00 \%$ & $\%$ & $5,6,9,40-46$ \\
\hline Proportion symptomatic at MM diagnosis & $87.50 \%$ & $\%$ & $47-50$ \\
\hline $\begin{array}{l}\text { Median duration for progression from } \\
\text { asymptomatic (smoldering) MM to } \\
\text { symptomatic MM }\end{array}$ & 58 & months & $47,48,50$ \\
\hline $\begin{array}{l}\text { MM-related death rate while asymptomatic } \\
\text { (smoldering), }<65 \text { years, MM patients }\end{array}$ & 0.0040 & $\begin{array}{l}\text { proportion per } \\
\text { year }\end{array}$ & 42,50 \\
\hline $\begin{array}{l}\text { MM-related death rate while asymptomatic } \\
\text { (smoldering), } \geq 65 \text { years, MM patients }\end{array}$ & 0.0400 & $\begin{array}{l}\text { proportion per } \\
\text { year }\end{array}$ & 42,50 \\
\hline $\begin{array}{l}\text { MM-related death rate while symptomatic } \\
\text { MM before treatment initiation, }<65 \text { years }\end{array}$ & 0.0045 & $\begin{array}{l}\text { proportion per } \\
\text { year }\end{array}$ & assumption \\
\hline $\begin{array}{l}\text { MM-related death rate while symptomatic } \\
\text { MM before treatment initiation, } \geq 65 \text { years }\end{array}$ & 0.0450 & $\begin{array}{l}\text { proportion per } \\
\text { year }\end{array}$ & assumption \\
\hline \multicolumn{4}{|l|}{ Treatment initiation } \\
\hline $\begin{array}{l}\text { Time from diagnosis of symptomatic MM to } \\
\text { treatment initiation }\end{array}$ & 0.500 & months & 42,45 \\
\hline Proportion $<65$ years initiating SCT pathway & $30.00 \%$ & $\%$ & 51,52 \\
\hline Proportion $\geq 65$ years initiating SCT pathway & $10.00 \%$ & $\%$ & 51,52 \\
\hline \multicolumn{4}{|l|}{$\begin{array}{l}\text { MM-related death rates on treatment } \\
\text { pathway }\end{array}$} \\
\hline $\begin{array}{l}\text { Patients }<65 \text { years, standard/low cytogenetic } \\
\text { risk, non-SCT treatment pathway: treatment } \\
\text { line } 1\end{array}$ & 0.10 & $\begin{array}{l}\text { Proportion per } \\
\text { year }\end{array}$ & 11,53 \\
\hline $\begin{array}{l}\text { MM-related death rate ratio: SCT compared } \\
\text { to non-SCT }\end{array}$ & 0.70 & None (ratio) & 9,54 \\
\hline $\begin{array}{l}\text { MM-related death rate ratio: } \geq 65 \text { year age } \\
\text { group compared to }<65 \text { year age group }\end{array}$ & 1.50 & None (ratio) & $9,49,52,55,56$ \\
\hline $\begin{array}{l}\text { MM-related death rate ratio: high cytogenetic } \\
\text { risk group compared to standard/low } \\
\text { cytogenetic risk group }\end{array}$ & 2.25 & None (ratio) & $6,40,41,46,54,57-59$ \\
\hline
\end{tabular}




\begin{tabular}{|c|c|c|c|}
\hline Parameter & Base Case & Units & Reference \\
\hline $\begin{array}{l}\text { MM-related death rate ratio: } 2 \text { nd line } \\
\text { compared to } 1 \text { st line treatment }\end{array}$ & 1.00 & None (ratio) & $1,15,60$ \\
\hline $\begin{array}{l}\text { MM-related death rate ratio: } 3 r d \text { line } \\
\text { compared to } 2 \text { nd line treatment }\end{array}$ & 1.10 & None (ratio) & $1,15,60$ \\
\hline $\begin{array}{l}\text { MM-related death rate ratio: } 4 \text { th line } \\
\text { compared to 3rd line treatment }\end{array}$ & 1.15 & None (ratio) & $1,15,60$ \\
\hline $\begin{array}{l}\text { MM-related death rate ratio: } 5 \text { th line } \\
\text { compared to } 4 \text { th line treatment }\end{array}$ & 1.20 & None (ratio) & $1,15,60$ \\
\hline $\begin{array}{l}\text { MM-related death rate ratio: } 6 \text { th line } \\
\text { compared to 5th line treatment }\end{array}$ & 1.25 & None (ratio) & $1,15,60$ \\
\hline $\begin{array}{l}\text { MM-related death rate ratio: } 7 \text { th line } \\
\text { compared to } 6 \text { th line treatment }\end{array}$ & 1.40 & None (ratio) & $1,15,60$ \\
\hline $\begin{array}{l}\text { MM-related death rate ratio: } 8 \text { th line } \\
\text { compared to } 7 \text { th line treatment (applicable to } \\
\text { subsequent lines, up to } 17 \text {, compared to the } \\
\text { previous line) }\end{array}$ & 1.50 & None (ratio) & $1,15,60$ \\
\hline \multicolumn{4}{|l|}{ Time to next line of treatment } \\
\hline $\begin{array}{l}\text { Treatment duration on treatment line } 1^{*} \\
\text { (patients }<65 \text { years, standard/low } \\
\text { cytogenetic risk, SCT pathway) }\end{array}$ & 35.0 & Months & $5,40,42,46,49,58,59,61,62$ \\
\hline $\begin{array}{l}\text { Time to next line of treatment: } n+1 \text { th line } \\
\text { compared to nth line treatment }\end{array}$ & 0.80 & None (ratio) & 41 \\
\hline $\begin{array}{l}\text { Time to next line of treatment: } \geq 65 \text { year age } \\
\text { group compared to }<65 \text { year age group }\end{array}$ & 0.75 & None (ratio) & 63,64 \\
\hline $\begin{array}{l}\text { Time to next line of treatment: high } \\
\text { cytogenetic risk group compared to } \\
\text { standard/low cytogenetic risk group }\end{array}$ & 0.45 & None (ratio) & $6,40,41,43,46,57,58$ \\
\hline $\begin{array}{l}\text { Treatment duration on treatment line } 1^{*} \\
\text { (patients }<65 \text { years, standard/low } \\
\text { cytogenetic risk, non-SCT pathway) }\end{array}$ & 27.0 & Months & $42,43,49,65,66$ \\
\hline
\end{tabular}

* Defined as time between initiating treatment line 1 and initiating treatment line 2. 
Table 2. Estimated Total Number of Prevalent MM Cases in the US by Line of Therapy and Patient Subgroups of Interest

\begin{tabular}{|c|c|c|c|c|c|c|c|c|c|}
\hline \multirow[t]{3}{*}{$\begin{array}{l}\text { Treatment } \\
\text { Line }\end{array}$} & \multirow[t]{3}{*}{ Total } & \multicolumn{4}{|c|}{ SCT Eligibility } & \multicolumn{4}{|c|}{ SCT Non Eligibility } \\
\hline & & \multicolumn{2}{|c|}{$\begin{array}{l}\text { Low/Standard } \\
\text { Cytogenetic } \\
\text { Risk }\end{array}$} & \multicolumn{2}{|c|}{$\begin{array}{c}\text { High } \\
\text { Cytogenetic } \\
\text { Risk }\end{array}$} & \multicolumn{2}{|c|}{$\begin{array}{l}\text { Low/Standard } \\
\text { Cytogenetic Risk }\end{array}$} & \multicolumn{2}{|c|}{$\begin{array}{c}\text { High } \\
\text { Cytogenetic } \\
\text { Risk }\end{array}$} \\
\hline & & $<65$ yrs & $\begin{array}{l}\geq 65 \\
\text { yrs }\end{array}$ & $\begin{array}{l}<65 \\
\text { yrs }\end{array}$ & $\geq 65$ yrs & $<65$ yrs & $\geq 65$ yrs & $\begin{array}{l}<65 \\
\text { yrs }\end{array}$ & $\begin{array}{l}\geq 65 \\
\text { yrs }\end{array}$ \\
\hline Line 1 & 23,629 & 3,375 & 1,196 & 825 & 306 & 6,000 & 8,351 & 1,465 & 2,111 \\
\hline Line 2 & 15,350 & 2,287 & 742 & 562 & 198 & 4,017 & 5,201 & 985 & 1,358 \\
\hline Line 3 & 10,249 & 1,584 & 477 & 390 & 132 & 2,746 & 3,346 & 676 & 898 \\
\hline Line 4 & 6,966 & 1,114 & 314 & 274 & 89 & 1,901 & 2,201 & 469 & 604 \\
\hline Line 5 & 4,786 & 790 & 210 & 193 & 61 & 1,325 & 1,469 & 328 & 410 \\
\hline Line 6 & 3,301 & 561 & 142 & 136 & 42 & 925 & 987 & 229 & 279 \\
\hline Line 7 & 2,252 & 394 & 95 & 95 & 28 & 637 & 657 & 158 & 188 \\
\hline Line 8 & 1,501 & 271 & 62 & 65 & 19 & 428 & 427 & 106 & 123 \\
\hline Line 9 & 971 & 181 & 40 & 43 & 12 & 279 & 269 & 69 & 78 \\
\hline Line 10 & 605 & 116 & 25 & 27 & 7 & 175 & 164 & 43 & 48 \\
\hline Line 11 & 363 & 72 & 15 & 17 & 4 & 106 & 95 & 26 & 28 \\
\hline Line 12 & 206 & 43 & 8 & 10 & 2 & 61 & 52 & 15 & 15 \\
\hline Line 13 & 111 & 24 & 5 & 5 & 1 & 33 & 27 & 8 & 8 \\
\hline Line 14 & 54 & 12 & 2 & 3 & 0 & 17 & 13 & 4 & 3 \\
\hline Line 15 & 23 & 6 & 1 & 1 & 0 & 8 & 5 & 1 & 1 \\
\hline Line 16 & 7 & 2 & 0 & 0 & 0 & 3 & 2 & 0 & 0 \\
\hline $\begin{array}{l}\text { Line } 17 \\
\text { and } \\
\text { greater }\end{array}$ & 2 & 1 & 0 & 0 & 0 & 1 & 0 & 0 & 0 \\
\hline $\begin{array}{l}\text { Total } \\
\text { patients } \\
\text { on } \\
\text { treatment }\end{array}$ & 70,375 & 10,833 & 3,333 & 2,646 & 901 & 18,662 & 23,266 & 4,582 & 6,152 \\
\hline
\end{tabular}


Table 3. Number of MM Patient Transitions in the US by Line of Therapy and Patient Subgroups of Interest

\begin{tabular}{|c|c|c|c|c|c|c|c|c|c|}
\hline \multirow{3}{*}{ New Treatment } & \multirow[b]{3}{*}{ Total } & \multicolumn{4}{|c|}{ SCT Eligibility } & \multicolumn{4}{|c|}{ SCT Non Eligibility } \\
\hline & & \multicolumn{2}{|c|}{$\begin{array}{l}\text { Low/standard } \\
\text { cytogenetic } \\
\text { risk }\end{array}$} & \multicolumn{2}{|c|}{$\begin{array}{c}\text { High } \\
\text { cytogenetic } \\
\text { risk }\end{array}$} & \multicolumn{2}{|c|}{$\begin{array}{l}\text { Low/standard } \\
\text { cytogenetic risk }\end{array}$} & \multicolumn{2}{|c|}{$\begin{array}{c}\text { High } \\
\text { cytogenetic risk }\end{array}$} \\
\hline & & $\begin{array}{l}<65 \\
\text { yrs }\end{array}$ & $\begin{array}{l}\geq 65 \\
\text { yrs }\end{array}$ & $\begin{array}{l}<65 \\
\text { yrs }\end{array}$ & $\begin{array}{l}\geq 65 \\
\text { yrs }\end{array}$ & $\begin{array}{l}<65 \\
\text { yrs }\end{array}$ & $\begin{array}{l}\geq 65 \\
\text { yrs }\end{array}$ & $\begin{array}{l}<65 \\
\text { yrs }\end{array}$ & $\begin{array}{l}\geq 65 \\
\text { yrs }\end{array}$ \\
\hline Line 1 & 18,689 & 1,418 & 742 & 763 & 399 & 3,309 & 6,680 & 1,781 & 3,597 \\
\hline Line 2 & 14,423 & 1,155 & 545 & 627 & 309 & 2,661 & 4,928 & 1,440 & 2,758 \\
\hline Line 3 & 11,677 & 979 & 422 & 533 & 250 & 2,227 & 3,837 & 1,210 & 2,219 \\
\hline Line 4 & 9,715 & 848 & 339 & 463 & 208 & 1,902 & 3,085 & 1,038 & 1,832 \\
\hline Line 5 & 8,225 & 746 & 278 & 406 & 176 & 1,646 & 2,535 & 900 & 1,538 \\
\hline Line 6 & 7,038 & 662 & 233 & 358 & 150 & 1,433 & 2,113 & 786 & 1,303 \\
\hline Line 7 & 6,047 & 589 & 196 & 316 & 129 & 1,250 & 1,773 & 686 & 1,108 \\
\hline Line 8 & 5,131 & 518 & 164 & 275 & 109 & 1,075 & 1,472 & 590 & 928 \\
\hline Line 9 & 4,241 & 444 & 134 & 234 & 90 & 900 & 1,192 & 493 & 754 \\
\hline Line 10 & 3,396 & 370 & 107 & 193 & 72 & 730 & 934 & 399 & 591 \\
\hline Line 11 & 2,616 & 298 & 82 & 153 & 55 & 571 & 704 & 310 & 443 \\
\hline Line 12 & 1,920 & 230 & 60 & 116 & 40 & 427 & 505 & 229 & 313 \\
\hline Line 13 & 1,334 & 169 & 42 & 84 & 28 & 303 & 342 & 160 & 206 \\
\hline Line 14 & 862 & 117 & 28 & 57 & 17 & 202 & 215 & 103 & 123 \\
\hline Line 15 & 511 & 76 & 17 & 35 & 10 & 125 & 124 & 60 & 64 \\
\hline Line 16 & 267 & 45 & 9 & 19 & 5 & 70 & 63 & 30 & 26 \\
\hline $\begin{array}{l}\text { Line } 17 \\
\text { and greater }\end{array}$ & 167 & 40 & 5 & 12 & 1 & 52 & 37 & 14 & 6 \\
\hline $\begin{array}{l}\text { Total } \\
\text { transitions }\end{array}$ & 96,259 & 8,704 & 3,403 & 4,644 & 2,048 & 18,883 & 30,539 & 10,229 & 17,809 \\
\hline
\end{tabular}


Table 4. Median and Credible Intervals of the Number of MM Patients and Number of Patient Transitions by Line of Therapy in the US

\begin{tabular}{|lccc|ccc|}
\hline & \multicolumn{3}{c}{ Number of MM Patients } & \multicolumn{3}{c|}{$\begin{array}{c}\text { Number } \text { of Patient Therapy Line } \\
\text { Transitions }\end{array}$} \\
\cline { 2 - 7 } Treatment Lines & Median & Lower & Upper & Median & Lower & Upper \\
\hline Line 1 & 23,584 & 22,236 & 25,029 & 18,696 & 18,558 & 18,817 \\
Line 2 & 15,346 & 13,845 & 16,760 & 14,415 & 13,489 & 15,176 \\
Line 3 & 10,234 & 8,908 & 11,515 & 11,658 & 10,348 & 12,811 \\
Line 4 & 6,955 & 5,847 & 8,053 & 9,699 & 8,223 & 11,085 \\
Line 5 & 4,778 & 3,893 & 5,685 & 8,214 & 6,670 & 9,744 \\
Line 6 & 3,298 & 2,609 & 4,038 & 7,028 & 5,483 & 8,630 \\
Line 7 & 2,252 & 1,723 & 2,850 & 6,042 & 4,531 & 7,669 \\
Line 8 & 1,502 & 1,106 & 1,975 & 5,131 & 3,695 & 6,766 \\
Line 9 & 975 & 687 & 1,338 & 4,244 & 2,919 & 5,872 \\
Line 10 & 612 & 409 & 886 & 3,403 & 2,223 & 4,964 \\
Line 11 & 369 & 232 & 568 & 2,629 & 1,612 & 4,075 \\
Line 12 & 213 & 125 & 353 & 1,937 & 1,107 & 3,273 \\
Line 13 & 116 & 63 & 210 & 1,350 & 714 & 2,487 \\
Line 14 & 59 & 30 & 119 & 878 & 428 & 1,788 \\
Line 15 & 28 & 13 & 63 & 525 & 236 & 1,212 \\
Line 16 & 12 & 5 & 32 & 279 & 120 & 719 \\
Line 17 and & 9 & 5 & 22 & 192 & 77 & 523 \\
greater & & & & & & \\
\hline
\end{tabular}




\section{Figure 1. Model to Assess Prevalence of Patients with MM at Different Treatment Lines}

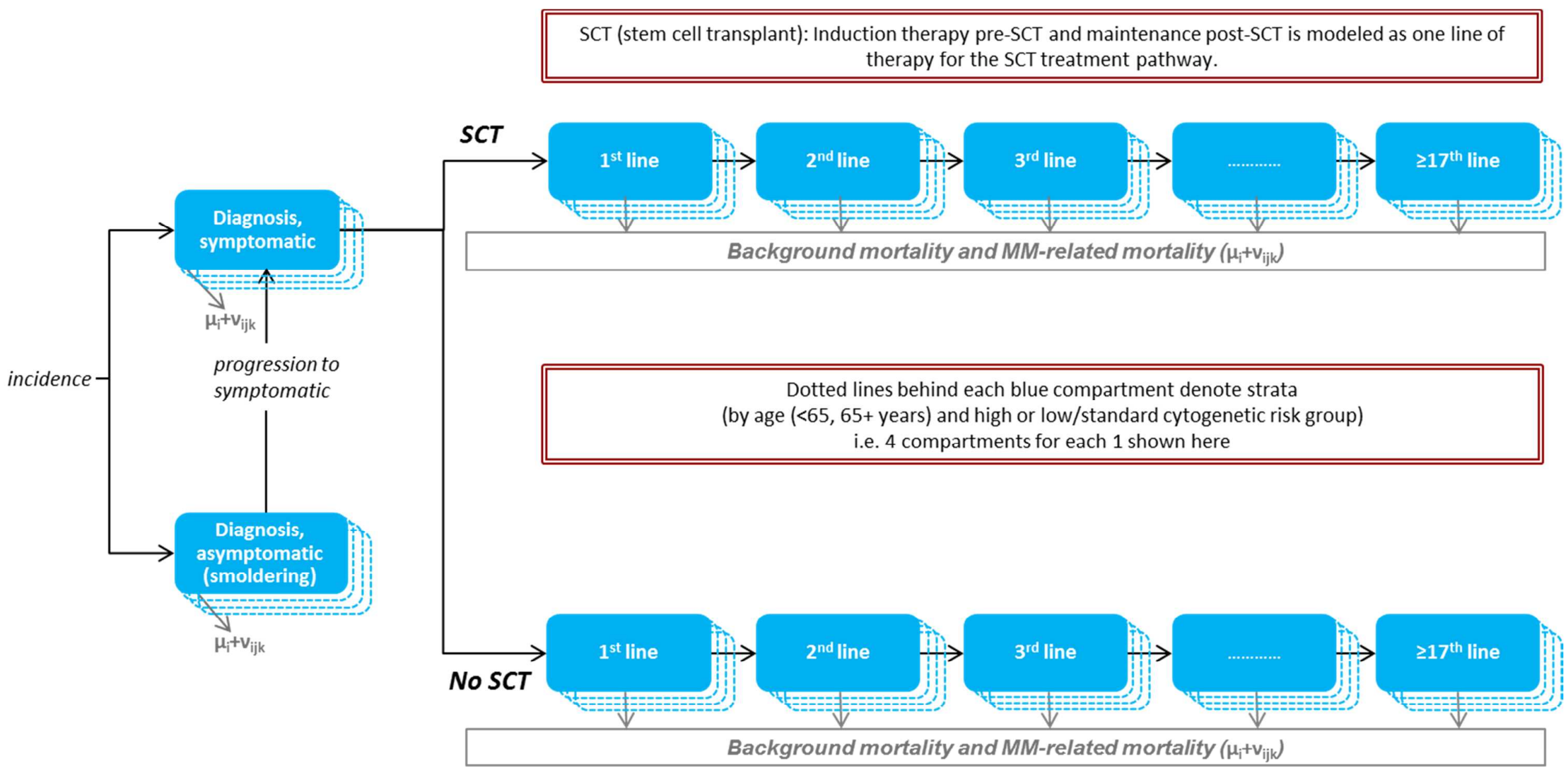

$\mu \mathrm{i}+\mathrm{vijk}$ - background and MM-related mortality. Subscripts denote differences in mortality rates by treatment state. e.g. mortality varies by SCT eligibility to reflect the higher frailty of SCT ineligible patients. 


\section{Appendix A: Model Parameters and Equations}

Table A - 1. Model Parameters

\begin{tabular}{|c|c|}
\hline & Description \\
\hline$\beta_{u}$ & Incidence of MM (all stages) for demographic group $u$ (proportion/year) \\
\hline $\boldsymbol{P}$ & Proportion of MM patients that is symptomatic at diagnosis* \\
\hline$K$ & Progression rate of asymptomatic MM to symptomatic* \\
\hline$\alpha$ & Progression rate of symptomatic MM to treatment ${ }^{\star}$ (per year) \\
\hline $\boldsymbol{\mu}_{\boldsymbol{u}}$ & Background death rate for demographic group $\boldsymbol{u}$ (per year) \\
\hline $\boldsymbol{\theta}_{\boldsymbol{u}}$ & $\begin{array}{l}\text { MM-related death rate for demographic group } \boldsymbol{u} \text { as yet untreated, asymptomatic (per } \\
\text { year) }\end{array}$ \\
\hline$\varphi_{u}$ & $\begin{array}{l}\text { MM-related death rate for demographic group } \boldsymbol{u} \text { as yet untreated, symptomatic MM (per } \\
\text { year) }\end{array}$ \\
\hline $\boldsymbol{\psi}_{u z}$ & $\begin{array}{l}\text { Proportion symptomatic initiating first line of treatment within demographic group } \boldsymbol{u} \\
\text { who are assigned to each treatment pathway }{ }^{1} \boldsymbol{Z}\end{array}$ \\
\hline$v_{u z w}$ & $\begin{array}{l}\text { MM-related death rate for demographic group } \boldsymbol{u} \text { on treatment pathway } \boldsymbol{Z} \text { and line of } \\
\text { therapy } \boldsymbol{w} \text { (per year) }\end{array}$ \\
\hline $1 / \gamma_{u z w}$ & $\begin{array}{l}\text { Time to next line of treatment for patients in demographic group } u \text { on treatment pathway } \\
\boldsymbol{Z} \text { and line of therapy } \boldsymbol{w} \text { (years) }\end{array}$ \\
\hline
\end{tabular}

$\mathrm{MM}=$ multiple myeloma

*Assumption that this parameter has the same value regardless of risk and age group.

†Demographic groups $=<65$ years and low/standard cytogenetic group; $\geq 65$ years and low/standard cytogenetic group; $<65$ years and high cytogenetic group; $\geq 65$ years and high cytogenetic group;

${ }^{1}$ Treatment pathways $=$ at least one SCT is performed; no SCT is performed

\section{Model Equations}

The model initiates upon diagnosis with MM. Individuals flow between states in the model. Patients may be diagnosed with asymptomatic $\left(\boldsymbol{A}_{\boldsymbol{u}}\right)$ or symptomatic $\left(\boldsymbol{S}_{\boldsymbol{u}}\right)$ MM, where u is demographic group (currently four groups according to age group and cytogenetic risk group). Asymptomatics $\left(\boldsymbol{A}_{\boldsymbol{u}}\right)$ receive new cases with proportion $(\mathbf{1}-\boldsymbol{P})$ of the total incidence $\boldsymbol{\beta}_{\boldsymbol{u}}$. Individuals become symptomatic at rate $\boldsymbol{K}$. Symptomatics $\left(\boldsymbol{S}_{\boldsymbol{u}}\right)$ receive a proportion $\boldsymbol{P}$ of the incident cases directly and initiate treatment at a rate $\boldsymbol{\alpha}$ with proportions $\boldsymbol{\psi}_{\boldsymbol{u z}}$ in each of the two treatment pathways. Asymptomatics experience MM-related mortality at rate $\boldsymbol{\theta}_{\boldsymbol{u}}$ whilst symptomatics experience MM-related mortality at rate $\boldsymbol{\varphi}_{\boldsymbol{u}}$. 
Each treatment state is represented by $\boldsymbol{T}_{\boldsymbol{u z} \boldsymbol{w}}$, where $\boldsymbol{u}$ is demographic group, $\boldsymbol{z}$ is treatment pathway (currently: 1 = at least one SCT is performed; $2=$ no SCT is performed), and $\boldsymbol{w}$ is line of therapy).Treated cases progress through 17 lines of treatment (index $\boldsymbol{w}$ from 1 to 17) at rate $\boldsymbol{\gamma}_{\boldsymbol{u z w}}$ and experience MM-related mortality at rate $\boldsymbol{v}_{\boldsymbol{u z w}}$. Asymptomatic, symptomatic, and treated individuals are all subject to background death rate $\boldsymbol{\mu}_{\boldsymbol{u}}$. Line of therapy is understood as one or more cycles of a planned treatment program (single agent, combination therapy, or sequence of treatments administered as planned). A new line of therapy is assumed to start when a planned treatment program is modified to include other drugs as a result of disease progression, relapse or toxicity, or when a planned period off-treatment is interrupted because additional treatment for MM is required. ${ }^{25}$

For patients undergoing SCTs, first-line treatment usually represents the package of treatments that are required for an SCT procedure (i.e., includes induction therapy as well as SCT). A second SCT is recorded as second-line treatment. In some cases, a first SCT could also take place at a line of therapy greater than line 1.

\section{Asymptomatic MM:}

$$
\frac{d A_{u}}{d t}=\beta_{u}(1-P)-A_{u}\left(K+\mu_{u}+\theta_{u}\right)
$$

Where $\boldsymbol{u}=1 \ldots 4$

Symptomatic MM, untreated:

$$
\frac{d \boldsymbol{S}_{u}}{d \boldsymbol{t}}=\boldsymbol{\beta}_{\boldsymbol{u}} \boldsymbol{P}+\boldsymbol{A}_{\boldsymbol{u}} \boldsymbol{K}-\boldsymbol{S}_{\boldsymbol{u}}\left(\boldsymbol{\alpha}+\boldsymbol{\mu}_{\boldsymbol{u}}+\boldsymbol{\varphi}_{\boldsymbol{u}}\right)
$$

Where $\boldsymbol{u}=1 \ldots 4$

\section{MM treatment stages}

First-line treatment:

$$
\frac{d \boldsymbol{T}_{u z w}}{d t}=\boldsymbol{S}_{u} \alpha \boldsymbol{\psi}_{u z}-\boldsymbol{T}_{u z w}\left(\mu_{u}+\boldsymbol{v}_{u z w}+\gamma_{u z w}\right)
$$

Where $\boldsymbol{u}=1 \ldots 4 ; \boldsymbol{z}=1,2 ; \boldsymbol{w}=1$

Subsequent treatment lines $(\boldsymbol{w}>1)$ : 


$$
\frac{d T_{u z w}}{d t}=T_{u z w-1} \gamma_{u z w-1}-T_{u z w}\left(\mu_{u}+v_{u z w}+\gamma_{u z w}\right)
$$

Where $\boldsymbol{u}=1 \ldots 4 ; \boldsymbol{z}=1,2 ; \boldsymbol{w}=2 \ldots 20$

The values of MM-related death rates and MM time to next treatment (TTNT) durations for each MM treatment state are related to a baseline MM-related death rate and two baseline time to next line of treatment values:

- The baseline MM-related death rate is for MM patients on the first line of treatment, on the non-SCT pathway, $<65$ years of age and in the low/standard cytogenetic risk group.

- MM-related death rates for all other treated MM health states are derived from the baseline rate using the following death rate relative risks $(R R)$ :

- $\quad R R$ for patients $\geq 65$ years compared to $<65$ years

- $\quad$ RR for patients in the high cytogenetic risk group compared to the low/standard-risk group

- $\quad$ RR for patients on the SCT pathway compared to those on the non-SCT pathway

- $\quad R R$ for patients on the $n+1^{\text {th }}$ line of treatment compared to those on the $n^{\text {th }}$ line of treatment

- The baseline TTNT values are for MM patients on the first line of treatment, < 65 years of age and in the low cytogenetic risk group. There is one baseline value for patients on the SCT treatment pathway and another value for patients on the nonSCT pathway.

- TTNT values for all other treated MM health states are derived from the baseline values using the following TTNT RRs:

- $\quad$ RR for patients $\geq 65$ years compared to $<65$ years

- RR for patients in the high cytogenetic risk group compared to the low/standard-risk group

- $\quad$ RR for patients on the $n+1$ th line of treatment compared to those on the $n$th line of treatment 


\section{Appendix B: Probabilistic Sensitivity Analysis}

Based on model influence diagram face validity discussions, the parameters expected to influence model output selected for inclusion in the PSA were:

Population inputs:

1. Proportion patients $<65$ years at MM diagnosis (prop_young in Figure B-1 below)

2. Proportion in low/standard cytogenetic risk group at MM diagnosis (prop_lowrisk)

3. Proportion symptomatic at MM diagnosis (prop_sympt)

Treatment inputs:

4. Proportion < 65 years initiating SCT pathway (prop_less65_SCT)

5. Baseline MM-related death rate; patients < 65 years, low/standard cytogenetic risk, non-SCT treatment pathway: treatment line 1 (baseline MM death rate)

6. MM-related death rate ratio: $\geq 65$ year age group compared to $<65$ year age group (RR_mort_oldage)

7. MM-related death rate ratio: high cytogenetic risk group compared to low/standard cytogenetic risk group (RR_mort_highrisk)

We used the LHS method ${ }^{30}$. Running the model with model parameters for the baseline country produced the PRCCs shown in Figure B-1. The magnitude of each PRCC quantifies the importance of each parameter, with the sign of the PRCC value indicating the specific qualitative relationship between the input and the output variable: positive values of PRCC imply that increasing the value of the input variable will lead to an increase in the output variable (number of forecasted patients with $\mathrm{MM}$ ). As a general rule, parameters with the largest influence are defined as those with a PRCC greater than 0.4 or less than -0.4 .

Figure B-1 shows that the parameters with the greatest influence on the model outcomes for the baseline country are all the MM-related death rates ratios [5-7 from list above], with the relationship being negative. Additionally, the proportion of patients in low cytogenetic risk group [2] and the proportion symptomatic [3] are shown to have a great positive influence on model outcomes. The observed low PRCCs for the proportion of young patients [1] and the proportion of young patients initiating SCT [4] imply that their influence on the model outcomes is expected to be low. 
1

2

3

4

5

6

7

8

9

10

11

12

13

14

15

16

17

18

19

20

21

22

23

24

25

26

27

28

29

30

31

32

33

34

35

36

37

38

39

40

41

42

43

44

45

46

47

48

49

50

51

52

53

54

55

56

57

58

59

60

Figure B-2. Partial Rank Correlation Coefficients for Key Model Parameters

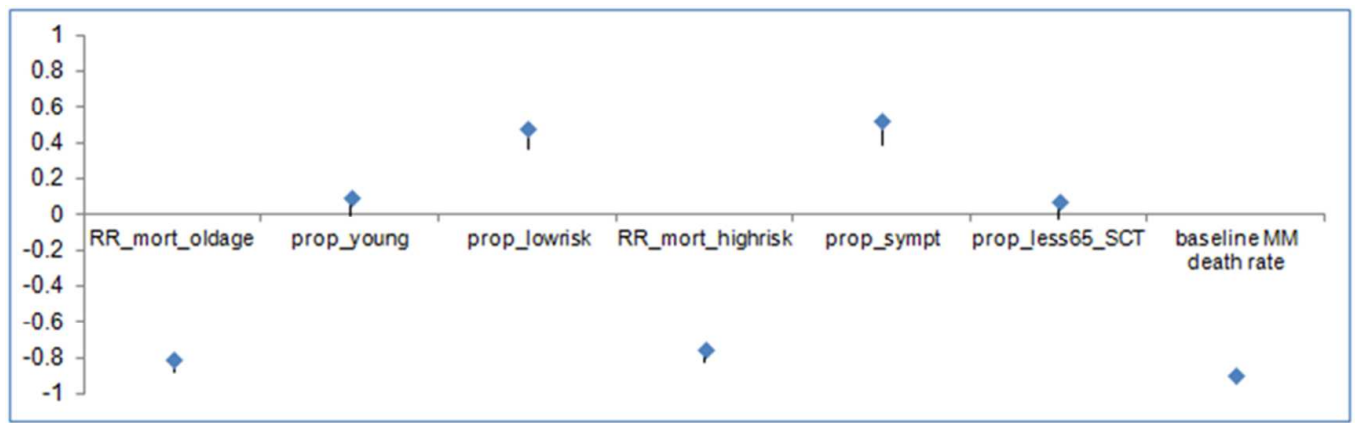

Table B - 2. Probabilistic Sensitivity Analysis Parameters

\begin{tabular}{|lccc|}
\hline Parameter (unit) & Base Case & $\begin{array}{c}\text { Standard } \\
\text { Error }\end{array}$ & Distribution \\
\hline Proportion patients $<65$ years at MM diagnosis & $38.00 \%$ & $1.80 \%$ & Beta \\
$\begin{array}{l}\text { Proportion in high cytogenetic risk group at } \\
\text { MM diagnosis }\end{array}$ & $35.00 \%$ & $2.50 \%$ & Beta \\
$\begin{array}{l}\text { Proportion symptomatic at MM diagnosis } \\
\text { Proportion <65 years initiating SCT pathway }\end{array}$ & $87.50 \%$ & $1.50 \%$ & Beta \\
$\begin{array}{l}\text { Proportion patients }<65 \text { years, standard/low } \\
\text { cytogenetic risk, non-SCT treatment pathway: }\end{array}$ & 0.100 & $2.5 \%$ & Beta \\
treatment line 1 & & 0.010 & Gamma \\
$\begin{array}{l}\text { MM-related death rate ratio: } \geq 65 \text { year age } \\
\text { group compared to <65 year age group }\end{array}$ & 1.50 & & \\
$\begin{array}{l}\text { MM-related death rate ratio: high cytogenetic } \\
\text { risk group compared to standard/low } \\
\text { cytogenetic risk group }\end{array}$ & 2.25 & 0.15 & Lognormal \\
\hline
\end{tabular}

http://mc.manuscifiptcentral.com/pds 


\section{Appendix C: PSA Results for Subgroups of Interest}

Table C - 1. Median and Credible Intervals of the Number of Patients and Number of Patient Transitions, by Line of Therapy: Patients $<65$ Years, Low/Moderate Cytogenetic Risk and Eligible for SCT.

\begin{tabular}{|lccc|ccc|}
\hline & \multicolumn{3}{c|}{ Number of Patients } & \multicolumn{3}{c|}{ Number of Patient Transitions } \\
\cline { 2 - 6 } Treatment Lines & Median & L5\% Credible Interval & \multicolumn{3}{c|}{ 95\% Credible Interval } \\
Line 1 & 3,357 & 2,792 & 4,030 & 1,414 & 1,177 & Upper \\
Line 2 & 2,270 & 1,882 & 2,773 & 1,150 & 956 & 1,380 \\
Line 3 & 1,570 & 1,284 & 1,929 & 972 & 806 & 1,187 \\
Line 4 & 1,099 & 887 & 1,363 & 840 & 687 & 1,032 \\
Line 5 & 774 & 618 & 976 & 734 & 593 & 911 \\
Line 6 & 548 & 431 & 702 & 646 & 515 & 814 \\
Line 7 & 384 & 297 & 503 & 570 & 449 & 732 \\
Line 8 & 263 & 200 & 351 & 499 & 386 & 653 \\
Line 9 & 175 & 129 & 240 & 425 & 324 & 568 \\
Line 10 & 113 & 81 & 159 & 353 & 261 & 485 \\
Line 11 & 70 & 49 & 102 & 283 & 204 & 398 \\
Line 12 & 42 & 28 & 64 & 218 & 151 & 320 \\
Line 13 & 24 & 15 & 39 & 160 & 107 & 247 \\
Line 14 & 13 & 8 & 22 & 111 & 70 & 182 \\
Line 15 & 7 & 4 & 12 & 72 & 43 & 128 \\
Line 16 & 3 & 2 & 6 & 43 & 24 & 83 \\
Line 17 and & 5 & 4 & 7 & 43 & 21 & 95 \\
greater & & & & & & \\
\hline
\end{tabular}


Table C - 2. Median and Credible Intervals of the Number of Patients and Number of Patient Transitions, by Line of Therapy: Patients $\geq 65$ Years, Low/Moderate Cytogenetic Risk and Eligible for SCT

\begin{tabular}{|lccc|ccc|}
\hline & \multicolumn{3}{c}{ Number of Patients } & \multicolumn{3}{c|}{ Number of Patient Transitions } \\
\cline { 2 - 7 } Treatment Lines & Median & L5\% Credible Interval & \multicolumn{3}{c|}{ 95\% Credible Interval } \\
\hline Line 1 & 1,195 & 1,080 & 1,316 & 744 & 682 & 798 \\
Line 2 & 740 & 643 & 846 & 545 & 492 & 600 \\
Line 3 & 475 & 396 & 561 & 421 & 366 & 482 \\
Line 4 & 314 & 248 & 383 & 338 & 282 & 400 \\
Line 5 & 210 & 159 & 265 & 279 & 221 & 341 \\
Line 6 & 142 & 102 & 186 & 233 & 176 & 294 \\
Line 7 & 95 & 65 & 129 & 197 & 141 & 257 \\
Line 8 & 63 & 40 & 90 & 165 & 112 & 223 \\
Line 9 & 41 & 24 & 61 & 135 & 86 & 193 \\
Line 10 & 25 & 14 & 41 & 108 & 63 & 163 \\
Line 11 & 15 & 8 & 27 & 83 & 45 & 135 \\
Line 12 & 9 & 4 & 17 & 62 & 30 & 108 \\
Line 13 & 5 & 2 & 10 & 43 & 19 & 83 \\
Line 14 & 3 & 1 & 6 & 29 & 11 & 61 \\
Line 15 & 2 & 1 & 4 & 17 & 6 & 42 \\
Line 16 & 1 & 1 & 2 & 10 & 3 & 26 \\
Line 17 and & 4 & 4 & 4 & 4 & 3 & 11 \\
greater & & & & & & \\
\hline
\end{tabular}


Table C - 3. Median and Credible Intervals of the Number of Patients and Number of Patient Transitions, by Line of Therapy: Patients $<65$ Years, High Cytogenetic Risk and Eligible for SCT

\begin{tabular}{|lccc|ccc|}
\hline & \multicolumn{3}{c|}{ Number of Patients } & \multicolumn{3}{c|}{ Number of Patient Transitions } \\
\cline { 2 - 7 } Treatment Lines & Median & Lower & Upper & Median & Lower & Upper \\
\hline Line 1 & 822 & 631 & 1,033 & 759 & 608 & 940 \\
Line 2 & 561 & 409 & 723 & 624 & 479 & 785 \\
Line 3 & 388 & 265 & 528 & 532 & 389 & 687 \\
Line 4 & 271 & 175 & 386 & 461 & 314 & 627 \\
Line 5 & 192 & 116 & 282 & 402 & 260 & 572 \\
Line 6 & 136 & 76 & 208 & 355 & 214 & 522 \\
Line 7 & 95 & 49 & 153 & 315 & 176 & 480 \\
Line 8 & 66 & 30 & 111 & 274 & 141 & 440 \\
Line 9 & 44 & 18 & 79 & 235 & 108 & 398 \\
Line 10 & 28 & 11 & 56 & 194 & 80 & 352 \\
Line 11 & 18 & 6 & 38 & 154 & 57 & 306 \\
Line 12 & 11 & 3 & 25 & 117 & 38 & 258 \\
Line 13 & 6 & 2 & 17 & 85 & 23 & 209 \\
Line 14 & 3 & 1 & 11 & 58 & 13 & 165 \\
Line 15 & 2 & 1 & 6 & 37 & 7 & 123 \\
Line 16 & 1 & 1 & 4 & 21 & 3 & 85 \\
Line 17 and & 4 & 4 & 5 & 8 & 3 & 42 \\
greater & & & & & & \\
\hline
\end{tabular}


Table C - 4. Median and Credible Intervals of the Number of Patients and Number of Patient Transitions, by Line of Therapy: Patients $\geq 65$ Years, High Cytogenetic Risk and Eligible for SCT

\begin{tabular}{|lccc|ccc|}
\hline & \multicolumn{3}{c|}{ Number of Patients } & \multicolumn{3}{c|}{ Number of Patient Transitions } \\
\cline { 2 - 7 } Treatment Lines & Median & Lower & Upper & Median & L5\% Credible Interval & Upper \\
\hline Line 1 & 305 & 252 & 362 & 400 & 344 & 457 \\
Line 2 & 199 & 148 & 247 & 308 & 254 & 366 \\
Line 3 & 133 & 89 & 174 & 251 & 186 & 312 \\
Line 4 & 90 & 55 & 124 & 209 & 140 & 274 \\
Line 5 & 62 & 34 & 90 & 177 & 108 & 243 \\
Line 6 & 43 & 22 & 66 & 151 & 84 & 220 \\
Line 7 & 29 & 14 & 47 & 130 & 67 & 200 \\
Line 8 & 20 & 8 & 34 & 110 & 51 & 179 \\
Line 9 & 13 & 5 & 24 & 91 & 37 & 160 \\
Line 10 & 8 & 3 & 17 & 73 & 26 & 140 \\
Line 11 & 5 & 2 & 12 & 56 & 17 & 119 \\
Line 12 & 3 & 1 & 8 & 41 & 10 & 98 \\
Line 13 & 2 & 1 & 5 & 28 & 6 & 78 \\
Line 14 & 1 & 1 & 3 & 18 & 3 & 59 \\
Line 15 & 1 & 1 & 2 & 10 & 2 & 41 \\
Line 16 & 1 & 1 & 2 & 5 & 1 & 26 \\
Line 17 and & 2 & 2 & 2 & 3 & 2 & 16 \\
greater & & & & & & \\
\hline
\end{tabular}


Table C - 5. Median and Credible Intervals of the Number of Patients and Number of Patient Transitions, by Line of Therapy: Patients $<65$ Years, Low/Moderate Cytogenetic Risk and Not Eligible for SCT

\begin{tabular}{|lccc|ccc|}
\hline & \multicolumn{3}{c}{ Number of Patients } & \multicolumn{3}{c|}{ Number of Patient Transitions } \\
\cline { 2 - 6 } Treatment Lines & Median & Lower & Upper & Median & Lower & Upper \\
\hline Line 1 & 6,011 & 5,350 & 6,686 & 3,309 & 2,967 & 3,675 \\
Line 2 & 4,024 & 3,519 & 4,526 & 2,667 & 2,373 & 2,966 \\
Line 3 & 2,757 & 2,373 & 3,136 & 2,232 & 1,951 & 2,510 \\
Line 4 & 1,906 & 1,614 & 2,211 & 1,911 & 1,644 & 2,173 \\
Line 5 & 1,330 & 1,106 & 1,567 & 1,651 & 1,398 & 1,915 \\
Line 6 & 929 & 760 & 1,118 & 1,439 & 1,196 & 1,696 \\
Line 7 & 641 & 512 & 792 & 1,256 & 1,027 & 1,512 \\
Line 8 & 430 & 335 & 549 & 1,081 & 864 & 1,336 \\
Line 9 & 281 & 211 & 371 & 905 & 704 & 1,154 \\
Line 10 & 176 & 129 & 242 & 735 & 553 & 971 \\
Line 11 & 107 & 74 & 154 & 574 & 418 & 789 \\
Line 12 & 62 & 41 & 93 & 431 & 299 & 622 \\
Line 13 & 34 & 21 & 55 & 307 & 204 & 464 \\
Line 14 & 18 & 10 & 30 & 205 & 128 & 331 \\
Line 15 & 9 & 5 & 16 & 128 & 75 & 221 \\
Line 16 & 4 & 2 & 8 & 72 & 39 & 137 \\
Line 17 and & 5 & 4 & 8 & 61 & 29 & 133 \\
greater & & & & & & \\
\hline
\end{tabular}


Table C - 6. Median and Credible Intervals of the Number of Patients and Number of Patient Transitions, by Line of Therapy: Patients $\geq 65$ Years, Low/Moderate Cytogenetic Risk and Not Eligible for SCT

\begin{tabular}{|lccc|ccc|}
\hline & \multicolumn{3}{c}{ Number of Patients } & \multicolumn{3}{c|}{ Number of Patient Transitions } \\
\cline { 2 - 6 } Treatment Lines & Median & Lower & Upper & Median & Lower & Upper \\
\hline Line 1 & 8,341 & 7,522 & 9,219 & 6,689 & 6,133 & 7,180 \\
Line 2 & 5,182 & 4,464 & 5,969 & 4,919 & 4,435 & 5,436 \\
Line 3 & 3,338 & 2,723 & 4,001 & 3,820 & 3,290 & 4,400 \\
Line 4 & 2,202 & 1,702 & 2,735 & 3,074 & 2,508 & 3,684 \\
Line 5 & 1,472 & 1,078 & 1,897 & 2,533 & 1,958 & 3,146 \\
Line 6 & 989 & 687 & 1,324 & 2,114 & 1,549 & 2,726 \\
Line 7 & 660 & 430 & 924 & 1,773 & 1,231 & 2,375 \\
Line 8 & 432 & 259 & 636 & 1,475 & 962 & 2,065 \\
Line 9 & 273 & 152 & 429 & 1,199 & 720 & 1,766 \\
Line 10 & 167 & 84 & 282 & 941 & 522 & 1,478 \\
Line 11 & 97 & 44 & 180 & 709 & 358 & 1,201 \\
Line 12 & 54 & 22 & 111 & 508 & 229 & 940 \\
Line 13 & 29 & 10 & 65 & 344 & 136 & 703 \\
Line 14 & 14 & 4 & 37 & 216 & 74 & 495 \\
Line 15 & 7 & 2 & 19 & 122 & 36 & 323 \\
Line 16 & 3 & 1 & 9 & 61 & 15 & 188 \\
Line 17 and & 3 & 3 & 7 & 33 & 7 & 130 \\
greater & & & & & & \\
\hline
\end{tabular}


Table C - 7. Median and Credible Intervals of the Number of Patients and Number of Patient Transitions, by Line of Therapy: Patients $<65$ Years, High Cytogenetic Risk and Not Eligible for SCT

\begin{tabular}{|lccc|ccc|}
\hline & \multicolumn{3}{c}{ Number of Patients } & \multicolumn{3}{c|}{ Number of Patient Transitions } \\
\cline { 2 - 6 } Treatment Lines & Median & Lower & Upper & Median & Lower & Upper \\
\hline Line 1 & 1,460 & 1,194 & 1,733 & 1,779 & 1,514 & 2,059 \\
Line 2 & 979 & 747 & 1,220 & 1,436 & 1,174 & 1,705 \\
Line 3 & 674 & 476 & 877 & 1,203 & 919 & 1,500 \\
Line 4 & 470 & 305 & 641 & 1,035 & 731 & 1,347 \\
Line 5 & 329 & 201 & 467 & 902 & 586 & 1,230 \\
Line 6 & 230 & 131 & 345 & 788 & 482 & 1,118 \\
Line 7 & 159 & 82 & 252 & 688 & 391 & 1,030 \\
Line 8 & 107 & 49 & 183 & 591 & 305 & 938 \\
Line 9 & 70 & 29 & 130 & 496 & 228 & 845 \\
Line 10 & 45 & 16 & 91 & 402 & 162 & 748 \\
Line 11 & 27 & 8 & 62 & 314 & 108 & 644 \\
Line 12 & 16 & 4 & 41 & 232 & 67 & 540 \\
Line 13 & 9 & 2 & 26 & 163 & 39 & 430 \\
Line 14 & 5 & 1 & 16 & 107 & 20 & 330 \\
Line 15 & 2 & 1 & 10 & 64 & 9 & 238 \\
Line 16 & 1 & 1 & 6 & 34 & 4 & 153 \\
Line 17 and & 3 & 3 & 6 & 6 & 2 & 43 \\
greater & & & & & & \\
\hline
\end{tabular}


Table C - 8. Median and Credible Intervals of the Number of Patients and Number of Patient Transitions, by Line of Therapy: Patients $\geq 65$ Years, High Cytogenetic Risk and Not Eligible for SCT

\begin{tabular}{|lccc|ccc|}
\hline & \multicolumn{3}{c}{ Number of Patients } & \multicolumn{3}{c|}{ Number of Patient Transitions } \\
\cline { 2 - 6 } Treatment Lines & Median & L5\% Credible Interval & \multicolumn{3}{c|}{$95 \%$ Credible Interval } \\
\hline Line 1 & 2,106 & 1,718 & 2,512 & 3,597 & 3,090 & 4,111 \\
Line 2 & 1,360 & 989 & 1,709 & 2,747 & 2,241 & 3,277 \\
Line 3 & 902 & 580 & 1,205 & 2,217 & 1,612 & 2,787 \\
Line 4 & 606 & 355 & 857 & 1,836 & 1,181 & 2,454 \\
Line 5 & 413 & 219 & 619 & 1,540 & 903 & 2,177 \\
Line 6 & 281 & 136 & 448 & 1,308 & 693 & 1,963 \\
Line 7 & 189 & 82 & 324 & 1,109 & 537 & 1,770 \\
Line 8 & 125 & 47 & 231 & 926 & 401 & 1,590 \\
Line 9 & 80 & 26 & 163 & 754 & 284 & 1,397 \\
Line 10 & 49 & 13 & 111 & 591 & 189 & 1,210 \\
Line 11 & 29 & 7 & 75 & 442 & 117 & 1,005 \\
Line 12 & 16 & 3 & 50 & 312 & 67 & 814 \\
Line 13 & 9 & 2 & 32 & 204 & 34 & 629 \\
Line 14 & 4 & 1 & 20 & 119 & 15 & 452 \\
Line 15 & 2 & 1 & 12 & 60 & 6 & 292 \\
Line 16 & 1 & 1 & 6 & 22 & 2 & 152 \\
Line 17 and & 1 & 1 & 2 & 4 & 1 & 39 \\
greater & & & & & & \\
\hline
\end{tabular}



therapy for the SCT treatment pathway.

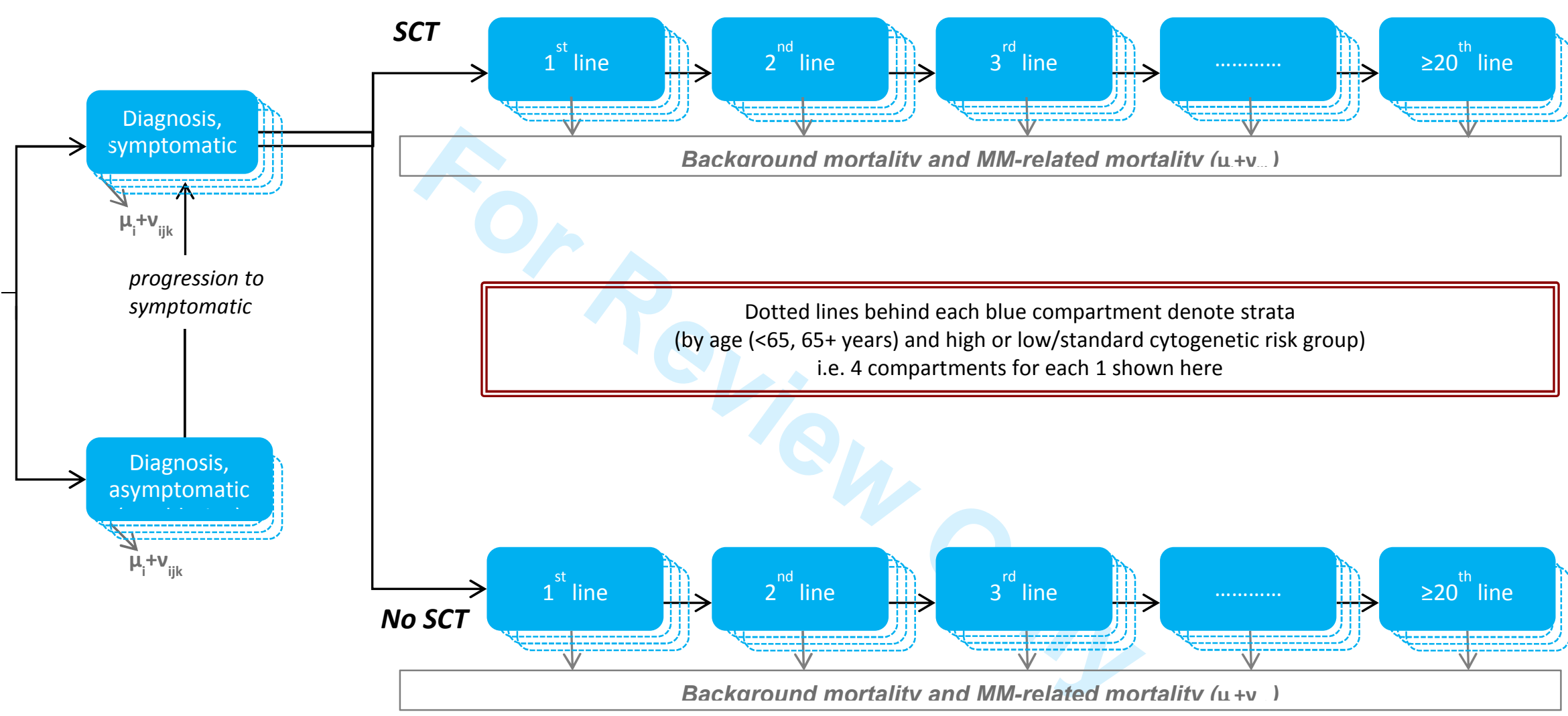

$\mu \mathrm{i}+\mathrm{vijk}$ - background and MM-related mortality. Subscripts denote differences in mortality rates by treatment state. e.g., mortality varies by SCT eligibility to reflect the higher frailty of SCT ineligible patients. 


\section{Page 37 of 50}

\section{Pharmacoepidemiology and Drug Safety}

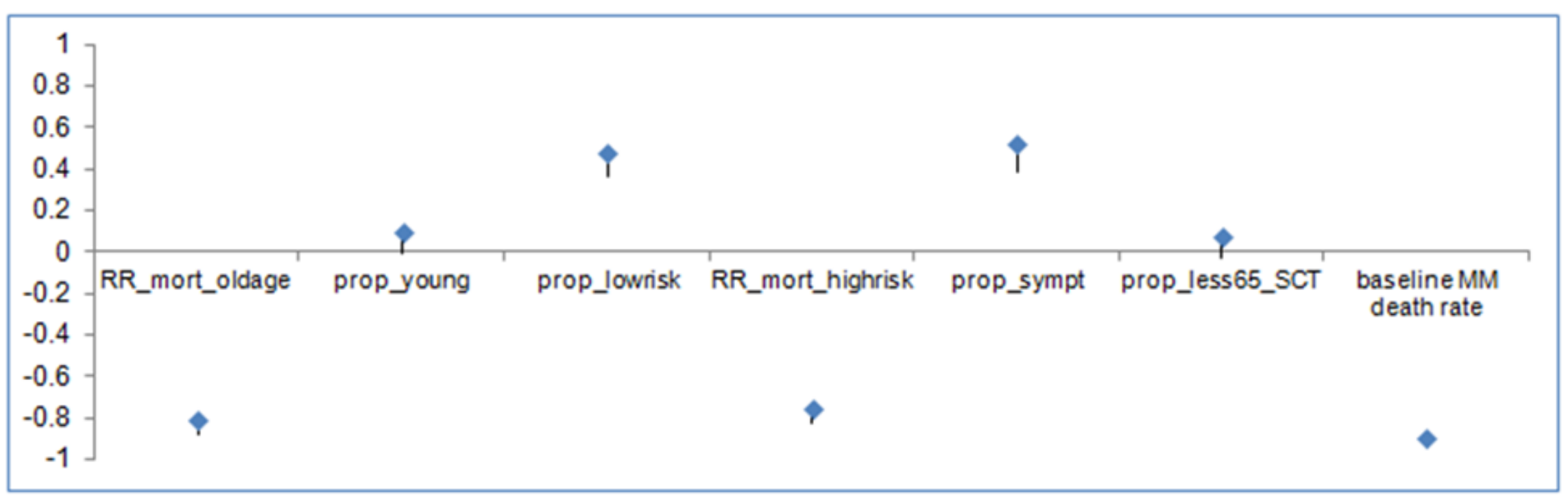

http://mc.manuscriptcentral.com/pds 


\section{CONFLICT OF INTEREST DISCLOSURE}

The Editors of Pharmacoepidemiology and Drug Safety recognize that most studies in pharmacoepidemiology cost money and thus pose a potential conflict of interest. As a conflict of interest may affect the assessment or judgment of an author, we ask that all authors (not just the Corresponding Author) complete the following form.

For Co-authors: Please complete questions 4-10. Completed forms should be saved, and emailed as an attachment to the Corresponding Author.

For Corresponding Authors: Please complete all questions. It is the responsibility of the Corresponding Author to submit completed forms on behalf of all co-authors via Manuscript Central at the point of manuscript submission.

\section{Corresponding author only (Co-authors go to Question 4):}

POTENTIAL STUDY INTERPRETATION CONFLICTS

1. Some or all of the data that were used in this study were provided by a company with a vested interest in the product being studied.

$n / a$

2. The sponsor of this project had the right of commenting but the authors retained the right to accept or reject comments or suggestions.

Yes

3. The sponsor of this project had the right of final editing and/or approval of the manuscript submitted.

No

\section{Corresponding author and Co-authors:}

POTENTIAL FINANCIAL CONFLICTS

4. I, my spouse, or one of my dependent children is an employee of a company whose product is being studied.

No

5. I, my spouse, or one of my dependent children has significant equity interest (>USD 10,000) in the company that owns the product being studied.

No 
6. In the past three years I have:

- been paid as a consultant (or in a similar capacity) by a company with a vested interest in the product being studied, on issues related to the product being studied; No

- been paid as a consultant (or in a similar capacity by a company with a vested interest in the product being studies, on issues unrelated to the product being studied; No

- received research or educational support from a company with a vested interest in the product(s) being studied.

No

7. A company whose product is being studied has provided funding to support the work on this project.

No

If you have answered YES to any of the above questions, or if you have additional personal, commercial or academic conflicts of interest, please draft a statement to publish with the article. e.g., AB has been reimbursed by Safe Drug Ltd. for international conference attendance.

Representatives of Onyx Pharmaceuticals, an Amgen subsidiary, participated in this project providing scientific advise, reviewing the model and commenting on the manuscript.

8. Manuscript title (first six words are sufficient)

Patient population with multiple myeloma and transitions across different lines of therapy in the US: an epidemiologic model

9. Author's full name (a separate form must be submitted for each author) Javier CID RUZAFA

10. In checking this box, I confirm I have completed this form to the best of my knowledge. $\bigotimes$

This form is available online by clicking here 


\section{CONFLICT OF INTEREST DISCLOSURE}

The Editors of Pharmacoepidemiology and Drug Safety recognize that most studies in pharmacoepidemiology cost money and thus pose a potential conflict of interest. As a conflict of interest may affect the assessment or judgment of an author, we ask that all authors (not just the Corresponding Author) complete the following form.

For Co-authors: Please complete questions 4-10. Completed forms should be saved, and emailed as an attachment to the Corresponding Author.

For Corresponding Authors: Please complete all questions. It is the responsibility of the Corresponding Author to submit completed forms on behalf of all co-authors via Manuscript Central at the point of manuscript submission.

\section{Corresponding author only (Co-authors go to Question 4):}

POTENTIAL STUDY INTERPRETATION CONFLICTS

1. Some or all of the data that were used in this study were provided by a company with a vested interest in the product being studied.

$n / a$

2. The sponsor of this project had the right of commenting but the authors retained the right to accept or reject comments or suggestions.

$\mathrm{n} / \mathrm{a}$

3. The sponsor of this project had the right of final editing and/or approval of the manuscript submitted.

$\mathrm{n} / \mathrm{a}$

\section{Corresponding author and Co-authors:}

POTENTIAL FINANCIAL CONFLICTS

4. I, my spouse, or one of my dependent children is an employee of a company whose product is being studied.

No

5. I, my spouse, or one of my dependent children has significant equity interest (>USD 10,000) in the company that owns the product being studied.

No 
6. In the past three years I have:

- been paid as a consultant (or in a similar capacity) by a company with a vested interest in the product being studied, on issues related to the product being studied; No

- been paid as a consultant (or in a similar capacity by a company with a vested interest in the product being studies, on issues unrelated to the product being studied; No

- received research or educational support from a company with a vested interest in the product(s) being studied.

No

7. A company whose product is being studied has provided funding to support the work on this project.

No

If you have answered YES to any of the above questions, or if you have additional personal, commercial or academic conflicts of interest, please draft a statement to publish with the article. e.g., AB has been reimbursed by Safe Drug Ltd. for international conference attendance.

Evie Merinopoulou has been an employee of Evidera and served as paid consultant to Onyx Pharmaceuticals for the work in this study.

8. Manuscript title (first six words are sufficient)

Patient population with multiple myeloma and transitions across different lines of therapy in the US: an epidemiologic model

9. Author's full name (a separate form must be submitted for each author)

Evie Merinopoulou

10. In checking this box, I confirm I have completed this form to the best of my knowledge. $\bigotimes$

This form is available online by clicking here 


\section{CONFLICT OF INTEREST DISCLOSURE}

The Editors of Pharmacoepidemiology and Drug Safety recognize that most studies in pharmacoepidemiology cost money and thus pose a potential conflict of interest. As a conflict of interest may affect the assessment or judgment of an author, we ask that all authors (not just the Corresponding Author) complete the following form.

For Co-authors: Please complete questions 4-10. Completed forms should be saved, and emailed as an attachment to the Corresponding Author.

For Corresponding Authors: Please complete all questions. It is the responsibility of the Corresponding Author to submit completed forms on behalf of all co-authors via Manuscript Central at the point of manuscript submission.

\section{Corresponding author only (Co-authors go to Question 4):}

POTENTIAL STUDY INTERPRETATION CONFLICTS

1. Some or all of the data that were used in this study were provided by a company with a vested interest in the product being studied.

$n / a$

2. The sponsor of this project had the right of commenting but the authors retained the right to accept or reject comments or suggestions.

$\mathrm{n} / \mathrm{a}$

3. The sponsor of this project had the right of final editing and/or approval of the manuscript submitted.

$\mathrm{n} / \mathrm{a}$

\section{Corresponding author and Co-authors:}

POTENTIAL FINANCIAL CONFLICTS

4. I, my spouse, or one of my dependent children is an employee of a company whose product is being studied.

No

5. I, my spouse, or one of my dependent children has significant equity interest (>USD 10,000) in the company that owns the product being studied.

No 
6. In the past three years I have:

- been paid as a consultant (or in a similar capacity) by a company with a vested interest in the product being studied, on issues related to the product being studied; No

- been paid as a consultant (or in a similar capacity by a company with a vested interest in the product being studies, on issues unrelated to the product being studied; No

- received research or educational support from a company with a vested interest in the product(s) being studied.

No

7. A company whose product is being studied has provided funding to support the work on this project.

No

If you have answered YES to any of the above questions, or if you have additional personal, commercial or academic conflicts of interest, please draft a statement to publish with the article. e.g., AB has been reimbursed by Safe Drug Ltd. for international conference attendance.

8. Manuscript title (first six words are sufficient)

Patient population with multiple myeloma and transitions across different lines of therapy in the US: an epidemiologic model

9. Author's full name (a separate form must be submitted for each author)

\section{Rebecca F Baggaley}

10. In checking this box, I confirm I have completed this form to the best of my knowledge. $\bigotimes$

This form is available online by clicking here 


\section{CONFLICT OF INTEREST DISCLOSURE}

The Editors of Pharmacoepidemiology and Drug Safety recognize that most studies in pharmacoepidemiology cost money and thus pose a potential conflict of interest. As a conflict of interest may affect the assessment or judgment of an author, we ask that all authors (not just the Corresponding Author) complete the following form.

For Co-authors: Please complete questions 4-10. Completed forms should be saved, and emailed as an attachment to the Corresponding Author.

For Corresponding Authors: Please complete all questions. It is the responsibility of the Corresponding Author to submit completed forms on behalf of all co-authors via Manuscript Central at the point of manuscript submission.

\section{Corresponding author only (Co-authors go to Question 4):}

POTENTIAL STUDY INTERPRETATION CONFLICTS

1. Some or all of the data that were used in this study were provided by a company with a vested interest in the product being studied.

$n / a$

2. The sponsor of this project had the right of commenting but the authors retained the right to accept or reject comments or suggestions.

$\mathrm{n} / \mathrm{a}$

3. The sponsor of this project had the right of final editing and/or approval of the manuscript submitted.

$\mathrm{n} / \mathrm{a}$

\section{Corresponding author and Co-authors:}

POTENTIAL FINANCIAL CONFLICTS

4. I, my spouse, or one of my dependent children is an employee of a company whose product is being studied.

No

5. I, my spouse, or one of my dependent children has significant equity interest (>USD 10,000) in the company that owns the product being studied.

No 
6. In the past three years I have:

- been paid as a consultant (or in a similar capacity) by a company with a vested interest in the product being studied, on issues related to the product being studied; No

- been paid as a consultant (or in a similar capacity by a company with a vested interest in the product being studies, on issues unrelated to the product being studied; No

- received research or educational support from a company with a vested interest in the product(s) being studied.

No

7. A company whose product is being studied has provided funding to support the work on this project.

No

If you have answered YES to any of the above questions, or if you have additional personal, commercial or academic conflicts of interest, please draft a statement to publish with the article. e.g., AB has been reimbursed by Safe Drug Ltd. for international conference attendance.

This work was funded by Onyx Pharmaceuticals. Leighton P was employed by Evidera and served as consultant to Onyx Pharmaceuticals.

8. Manuscript title (first six words are sufficient)

Patient population with multiple myeloma and transitions across different lines of therapy in the US: an epidemiologic model

9. Author's full name (a separate form must be submitted for each author)

Pamela Leighton

10. In checking this box, I confirm I have completed this form to the best of my knowledge. $\square$

This form is available online by clicking here 


\section{CONFLICT OF INTEREST DISCLOSURE}

The Editors of Pharmacoepidemiology and Drug Safety recognize that most studies in pharmacoepidemiology cost money and thus pose a potential conflict of interest. As a conflict of interest may affect the assessment or judgment of an author, we ask that all authors (not just the Corresponding Author) complete the following form.

For Co-authors: Please complete questions 4-10. Completed forms should be saved, and emailed as an attachment to the Corresponding Author.

For Corresponding Authors: Please complete all questions. It is the responsibility of the Corresponding Author to submit completed forms on behalf of all co-authors via Manuscript Central at the point of manuscript submission.

\section{Corresponding author only (Co-authors go to Question 4):}

POTENTIAL STUDY INTERPRETATION CONFLICTS

1. Some or all of the data that were used in this study were provided by a company with a vested interest in the product being studied.

$n / a$

2. The sponsor of this project had the right of commenting but the authors retained the right to accept or reject comments or suggestions.

$\mathrm{n} / \mathrm{a}$

3. The sponsor of this project had the right of final editing and/or approval of the manuscript submitted.

\section{Corresponding author and Co-authors:}

POTENTIAL FINANCIAL CONFLICTS

4. I, my spouse, or one of my dependent children is an employee of a company whose product is being studied.

Yes

5. I, my spouse, or one of my dependent children has significant equity interest (>USD 10,000) in the company that owns the product being studied.

Yes 
6. In the past three years I have:

- been paid as a consultant (or in a similar capacity) by a company with a vested interest in the product being studied, on issues related to the product being studied; No

- been paid as a consultant (or in a similar capacity by a company with a vested interest in the product being studies, on issues unrelated to the product being studied; No

- received research or educational support from a company with a vested interest in the product(s) being studied.

No

7. A company whose product is being studied has provided funding to support the work on this project.

No

If you have answered YES to any of the above questions, or if you have additional personal, commercial or academic conflicts of interest, please draft a statement to publish with the article. e.g., AB has been reimbursed by Safe Drug Ltd. for international conference attendance.

I am an employee of Onyx Pharmaceuticals, an Amgen Subsidiary, who funded this research.

8. Manuscript title (first six words are sufficient)

Patient population with multiple myeloma and transitions across different lines of therapy in the US: an epidemiologic model

9. Author's full name (a separate form must be submitted for each author)

Winifred Werther

10. In checking this box, I confirm I have completed this form to the best of my knowledge. $\bigotimes$

This form is available online by clicking here 


\section{CONFLICT OF INTEREST DISCLOSURE}

The Editors of Pharmacoepidemiology and Drug Safety recognize that most studies in pharmacoepidemiology cost money and thus pose a potential conflict of interest. As a conflict of interest may affect the assessment or judgment of an author, we ask that all authors (not just the Corresponding Author) complete the following form.

For Co-authors: Please complete questions 4-10. Completed forms should be saved, and emailed as an attachment to the Corresponding Author.

For Corresponding Authors: Please complete all questions. It is the responsibility of the Corresponding Author to submit completed forms on behalf of all co-authors via Manuscript Central at the point of manuscript submission.

\section{Corresponding author only (Co-authors go to Question 4):}

POTENTIAL STUDY INTERPRETATION CONFLICTS

1. Some or all of the data that were used in this study were provided by a company with a vested interest in the product being studied.

$n / a$

2. The sponsor of this project had the right of commenting but the authors retained the right to accept or reject comments or suggestions.

$\mathrm{n} / \mathrm{a}$

3. The sponsor of this project had the right of final editing and/or approval of the manuscript submitted.

\section{Corresponding author and Co-authors:}

POTENTIAL FINANCIAL CONFLICTS

4. I, my spouse, or one of my dependent children is an employee of a company whose product is being studied.

Yes

5. I, my spouse, or one of my dependent children has significant equity interest (>USD 10,000) in the company that owns the product being studied.

Yes 
6. In the past three years I have:

- been paid as a consultant (or in a similar capacity) by a company with a vested interest in the product being studied, on issues related to the product being studied; Yes

- been paid as a consultant (or in a similar capacity by a company with a vested interest in the product being studies, on issues unrelated to the product being studied; Yes

- received research or educational support from a company with a vested interest in the product(s) being studied.

No

7. A company whose product is being studied has provided funding to support the work on this project.

No

If you have answered YES to any of the above questions, or if you have additional personal, commercial or academic conflicts of interest, please draft a statement to publish with the article. e.g., AB has been reimbursed by Safe Drug Ltd. for international conference attendance.

I have been paid as a consultant (or in a similar capacity) by Onyx, a subsidiary of Amgen, with a vested interest in the product being studied.

8. Manuscript title (first six words are sufficient)

Patient population with multiple myeloma and transitions across different lines of therapy in the US: an epidemiologic model

9. Author's full name (a separate form must be submitted for each author)

Diana Felici

10. In checking this box, I confirm I have completed this form to the best of my knowledge. $\bigotimes$

This form is available online by clicking here 


\section{CONFLICT OF INTEREST DISCLOSURE}

The Editors of Pharmacoepidemiology and Drug Safety recognize that most studies in pharmacoepidemiology cost money and thus pose a potential conflict of interest. As a conflict of interest may affect the assessment or judgment of an author, we ask that all authors (not just the Corresponding Author) complete the following form.

For Co-authors: Please complete questions 4-10. Completed forms should be saved, and emailed as an attachment to the Corresponding Author.

For Corresponding Authors: Please complete all questions. It is the responsibility of the Corresponding Author to submit completed forms on behalf of all co-authors via Manuscript Central at the point of manuscript submission.

\section{Corresponding author only (Co-authors go to Question 4):}

POTENTIAL STUDY INTERPRETATION CONFLICTS

1. Some or all of the data that were used in this study were provided by a company with a vested interest in the product being studied.

$n / a$

2. The sponsor of this project had the right of commenting but the authors retained the right to accept or reject comments or suggestions.

$\mathrm{n} / \mathrm{a}$

3. The sponsor of this project had the right of final editing and/or approval of the manuscript submitted.

$\mathrm{n} / \mathrm{a}$

\section{Corresponding author and Co-authors:}

POTENTIAL FINANCIAL CONFLICTS

4. I, my spouse, or one of my dependent children is an employee of a company whose product is being studied.

No

5. I, my spouse, or one of my dependent children has significant equity interest (>USD 10,000) in the company that owns the product being studied.

No 
6. In the past three years I have:

- been paid as a consultant (or in a similar capacity) by a company with a vested interest in the product being studied, on issues related to the product being studied; No

- been paid as a consultant (or in a similar capacity by a company with a vested interest in the product being studies, on issues unrelated to the product being studied; No

- received research or educational support from a company with a vested interest in the product(s) being studied.

No

7. A company whose product is being studied has provided funding to support the work on this project.

No

If you have answered YES to any of the above questions, or if you have additional personal, commercial or academic conflicts of interest, please draft a statement to publish with the article. e.g., AB has been reimbursed by Safe Drug Ltd. for international conference attendance.

8. Manuscript title (first six words are sufficient)

Patient population with Multiple Myeloma and

9. Author's full name (a separate form must be submitted for each author)

Andrew Paul Cox

10. In checking this box, I confirm I have completed this form to the best of my knowledge. $\square$

This form is available online by clicking here 